Article

\title{
Glacier Monitoring Using Frequency Domain Offset Tracking Applied to Sentinel-1 Images: A Product Performance Comparison
}

\author{
Donato Amitrano ${ }^{1, *(1)}$, Raffaella Guida ${ }^{1}$, Gerardo Di Martino ${ }^{2}(\mathbb{D})$ and Antonio Iodice ${ }^{2}$ \\ 1 Surrey Space Centre, University of Surrey, Guildford GU2 7XH, UK; r.guida@surrey.ac.uk \\ 2 University of Napoli Federico II, Department of Electrical Engineering and Information Technology, \\ Via Claudio 21, 80125 Napoli, Italy; gerardo.dimartino@unina.it (G.D.M.); iodice@unina.it (A.I.) \\ * Correspondence: d.amitrano@surrey.ac.uk
}

Received: 4 April 2019; Accepted: 29 May 2019; Published: 1 June 2019

\begin{abstract}
The Sentinel-1 mission has now reached its maturity, and is acquiring high-quality images with a high revisit time, allowing for effective continuous monitoring of our rapidly changing planet. The purpose of this work is to assess the performance of the different synthetic aperture radar products made available by the European Space Agency through the Sentinels Data Hub against glacier displacement monitoring with offset tracking methodology. In particular, four classes of products have been tested: the medium resolution ground range detected, the high-resolution ground range detected, acquired in both interferometric wide and extra-wide swath, and the single look complex. The first are detected pre-processed images with about 40, 25, and 10-m pixel spacing, respectively. The last category, the most commonly adopted for the application at issue, represents the standard coherent synthetic aperture radar product, delivered in unprocessed focused complex format with pixel spacing ranging from 14 to $20 \mathrm{~m}$ in azimuth and from approximately 2 to $6 \mathrm{~m}$ in range, depending on the acquisition area and mode. Tests have been performed on data acquired over four glaciers, i.e., the Petermann Glacier, the Nioghalvfjerdsfjorden, the Jackobshavn Isbræ and the Thwaites Glacier. They revealed that the displacements estimated using interferometric wide swath single look complex and high-resolution ground range detected products are fully comparable, even at computational level. As a result, considering the differences in memory consumption and pre-processing requirements presented by these two kinds of product, detected formats should be preferred for facing the application.
\end{abstract}

Keywords: synthetic aperture radar; offset tracking; displacements; Sentinel-1; glacier monitoring

\section{Introduction}

Under the aegis of the Copernicus Programme, the Sentinel-1 (S1) mission of the European Space Agency (ESA) has been providing high quality synthetic aperture radar (SAR) images since 2014 . The short revisit time and the free and open data distribution policy is substantially affecting the remote sensing downstream sector, with more and more users involved in an increasing number of applications [1].

The $\mathrm{S} 1$ mission acquires data in different modes resulting in products at different spatial resolutions. The most commonly used are the interferometric wide (IW) swath and the interferometric extra-wide (EW) swath, in which data are acquired in swaths using the Terrain Observation with Progressive Scanning SAR (TOPSAR) imaging technique [2]. Raw products are then processed and uploaded on the Sentinels Data Hub (SDH) in two different formats: the single look complex (SLC) data format, and the ground range detected (GRD) data format [3]. 
SLC images represent the standard SAR product [4]. The products are in zero-doppler geometry. Each row of pixels represents points along a line perpendicular to the sub-satellite track. The products include a single look in each dimension, using the full available signal bandwidth and complex samples preserving the phase information. For IW and EW acquisition modes, each sub-swath consists of a series of bursts. Each burst is processed as a separate SLC image, and all processed bursts are finally assembled into the final product [3]. In the first case, the pixel spacing is approximately $14 \times 2 \mathrm{~m}$ in azimuth/slant range directions. In the latter, it is approximately $6 \times 20 \mathrm{~m}$.

GRD products are detected, multi-looked and projected onto ground range (using an Earth ellipsoid model) images. Ground range coordinates are the slant range coordinates projected onto the Earth's ellipsoid. The phase information originally contained in SLC products is not preserved. The resulting product has approximately square resolution cell and square pixel spacing with reduced speckle at a cost of reduced geometric resolution. These products are provided in three different formats: the full resolution ground range detected (GRDF), the high-resolution ground range detected $(\mathrm{GRDH})$, and the medium resolution ground range detected (GRDM).

GRDF products present a pixel spacing of $3.5 \mathrm{~m}$ in azimuth/slant range directions and derive only from stripmap (SM) acquisitions, which are scarcely tasked at the time of this research. GRDH products have a pixel spacing of approximately $10 \mathrm{~m}$ in azimuth/slant range directions when derived from SM or IW acquisitions, and up to about $25 \mathrm{~m}$ when images come from EW data. Finally, GRDM products present 40-m pixel spacing roughly when acquired both in IW and EW mode. For a complete reference concerning S1 products and acquisition modality, the reader should refer to $[3,5]$.

Given the variety of S1 products, it is important to identify the best among them in feeding information extraction algorithms and to assess each performance in relation to a specific application [6] or image quality parameter [7]. This work has two main objectives: the first one is to assess the performance of the three most available products in the SDH, namely the SLCs, the GRDHs, and the GRDMs, with regard to a classic SAR remote sensing application, which is glacier displacement monitoring with offset tracking (OT) [8-10]. The second one is to provide users and scientists interested in this application with some guidelines concerning the exploitation of different products and the best parameters setting based on quantitative analysis of the estimated displacements. The test cases here concern four of the largest worldwide glaciers i.e., the Petermann Glacier (PG), the Nioghalvfjerdsfjorden (NI), the Jackobshavn Isbræ (JAK) and the Thwaites Glacier (THW). The first three are in the Greenland and the last in Antarctica. Displacements have been measured by processing 24 images per product class in pairs, approximately a couple per month, during the year 2017.

Remote sensing technologies have been widely exploited for monitoring glaciers at continental scale since the 1980s [11,12]. At that time, displacements were estimated through manual feature tracking of natural color images acquired with long temporal baseline. From the 1990s, the literature started to propose methodologies able to automatically track displacements exploiting correlation of multispectral images [13-15].

Due to the large availability of free images, multispectral sensors were the privileged source of data. Landsat 4 and 5 acquisitions were exploited to map displacements of the Ross [16] and Larsen [17] ice shelves in Antarctica. Landsat 8 images were preferred for large scale mapping of ice flows of Greenland, Antarctica and Alaska $[18,19]$. For estimation of ice velocity in Antarctica MODIS-based mosaics were employed [20]. Historical trends of the Pamir-Karakoram-Himalaya system were retrieved from archive Landsat 5 and 7 data [21]. The suitability of data acquired by the recently launched Sentinel-2 satellite with glacier monitoring (not limited to displacements) was investigated in [22]. A data performance comparison between Sentinel-2 and Landsat was provided in [23].

Due to the dependence upon light and weather conditions of passive sensors (which is particularly severe at very high/very low latitudes [24]) SAR sensors have been widely preferred for glaciers monitoring since the 1990s with the launch of the ERS-1 satellite. As explained in Joughin et al. [25], initially SAR interferometry was exploited to map displacements [26-28]. However, these techniques have limitations when applied to large displacements as discussed in the following Section. Therefore, 
intensity tracking methods, originally developed for multispectral data, started being developed to deal with large displacements. OT methods have been successfully applied to map movements of terrains due to natural phenomena such as landslides, earthquakes [29-31], human activities (e.g., mining) [32,33] and glaciers [8-10,34-37]. In this paper, the technique is applied to pairs of S1 images acquired in different modalities to assess the performance of the different product classes and determine the best in terms of accuracy of the estimated displacements and computational demand.

The work is organized as follows. Materials and methods are introduced in Section 2. Experimental results are presented and commented in Section 3 according to inter-product comparison and comparison with literature. It is worth stressing that the analysis has been performed from a data product perspective only. In other words, the paper does not contain any physical interpretation of the phenomenon considered (i.e., why glaciers move in one or another direction) but can advise an expert in the field of the best $\mathrm{S} 1$ products to infer similar conclusions.

\section{Materials and Methods}

\subsection{Offset Tracking}

OT methods allow for large displacements estimation without the need to exploit the SAR phase information. In this sense, they can be seen as complementary to classic differential synthetic aperture radar interferometry (DInSAR) [38]. As is well-known, DInSAR-based estimations are limited in the maximum observable displacement gradient (depending on the signal wavelength) and on the preservation of the interferometric coherence. Hence, it is typically applied only on areas exhibiting high temporal stability with respect to the signal phase (e.g., slow subsidence or buildings) [29]. Moreover, classic DInSAR can measure just displacements in the slant range direction, so no information concerning horizontal movements can be provided unless special techniques (such as the one proposed in [39]) are applied.

OT methods, instead, are applied to the SAR amplitude channel, thus being less sensitive to atmospheric effects and insensitive to phase instability of targets. They allow for measuring South-North and East-West displacements without any limitation on the observable gradient and even in areas typically characterized by low interferometric coherence, such as those highly vegetated [40]. This means that, by using just a couple of SAR images, movements of several meters can be detected with a good degree of approximation [31].

The block diagram of the implemented frequency-domain OT technique is depicted in Figure 1. It starts with a couple of SAR images as input to a coregistration block. The image acquired first is the reference for the displacements estimation and it is called master. The image in which displacements are evaluated is referred to as the slave image. They are co-registered with standard techniques [4]. When S1 data are selected, the application of precise orbit [41], if available, is advised before co-registration.

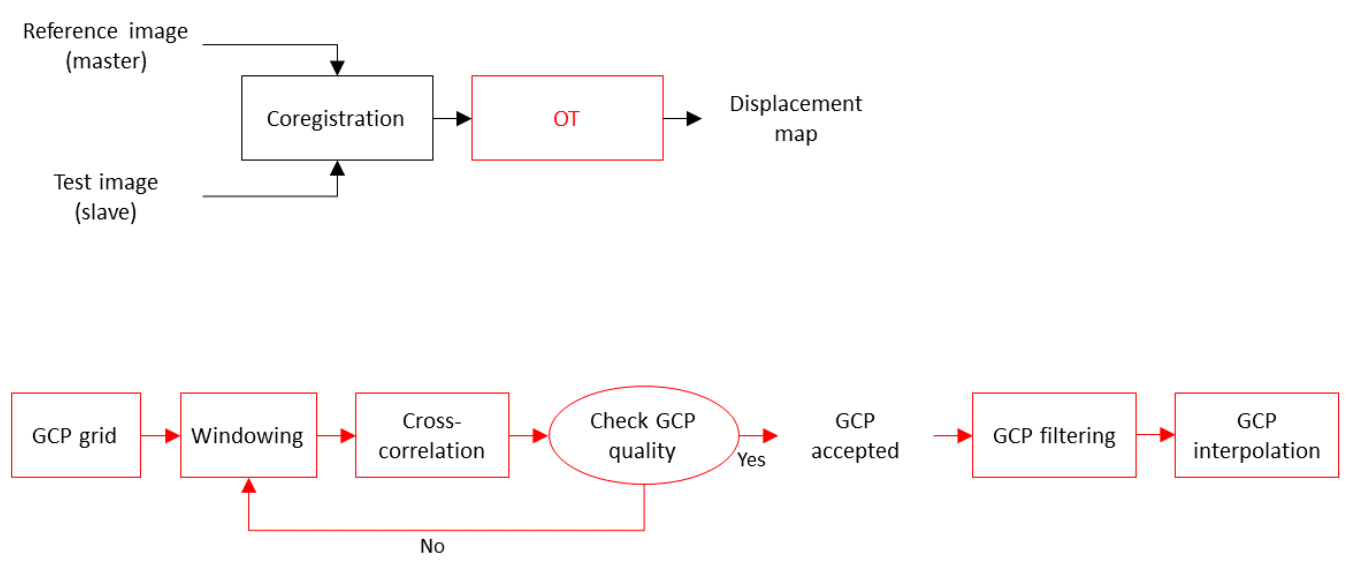

Figure 1. Block diagram of the implemented frequency-domain offset tracking (OT) technique. The lower diagram is an exploded view of the OT processing block. 
Co-registered data feed the OT algorithm depicted in the lower diagram of Figure 1 [29]. It exploits cross-correlation (CC) calculated on several windows extracted from the image pair to estimate the shift between the master patch and the slave patch. Windows are extracted around grid-points (or ground control points, GCPs) usually regularly distributed across the images.

The CC matrix $C$ between two null-mean patches $M$ and $S$ from, respectively, the master and slave image, is computed as follows:

$$
C=\frac{\operatorname{IFFT}\left\{\operatorname{FFT}\{M\} \times \operatorname{FFT}\{S\}^{*}\right\}}{\sqrt{\left\langle M^{2}\right\rangle \times\left\langle S^{2}\right\rangle}}, C \in[0,1]
$$

in which FFT and IFFT stand for the fast Fourier and the inverse fast Fourier transforms, respectively, the apex * represents the complex conjugation operation, and the symbol $\left.<^{*}\right\rangle$ the mean operator. In Equation (1), $M$ and $S$ are oversampled by a factor $f$ (which must be a power of two in order to optimize the FFT calculation) to take into account the sub-pixel movements, being the minimum detectable displacement (in pixel units), i.e., the technique sensitivity, equal to $1 / f$.

The peak value of the matrix $C, c_{\max }$, identifies the amount of the shift to be applied to the slave patch to be superimposed to the master one. The higher the peak, the more reliable the estimated shift is. Note that $C$ is a circular matrix, therefore the maximum detectable shift is equal to $\pm d / 2$, where $d$ is the dimension of the patches.

In order to identify reliable shifts, two quality parameters for the selection of reliable GCPs, i.e., the peak value $c_{\max }$ previously introduced and the ratio $q=c_{\max } /\langle C\rangle$ between the matrix peak and the background, are considered [9]. For both parameters, a pre-determined user-defined threshold is adopted to exclude invalid GCPs. Spatial smoothing filter is usually applied to minimize noisy displacement patterns and reduce high-frequency noise [31]. Accepted GCPs are finally interpolated to produce the displacement map. Due to interpolation it is possible that they show displacement values under the sensitivity of the method dictated by the oversampling factor.

\subsection{Algorithm Set-Up}

In Table 1, the OT algorithm parameters setting for the implemented experiments are reported. They vary as a function of the product class. The objective was to obtain output maps with comparable sensitivity, i.e., with a minimum detectable displacement of the same order. Accordingly, due to the different pixel spacing of the input products, a different parameters set-up was chosen for the grid spacing, the oversampling factor and the cross-correlation window size. In the table, when the values relevant to the sensitivity and the CC window size are in square brackets they refer to a range of possible values used to set-up different experiments, which details are reported in Section 4.

As for the grid spacing, it was slightly increased as the product pixel spacing decreases in order to reduce the computational load. In fact, the number of GCPs to be evaluated is given by the size of the analyzed subset divided by the grid spacing. Intuitively, as the image resolution improves, the subset size enclosing the glacier increases as well. Therefore, a less dense grid was preferred when running the OT on the products with higher resolution.

The oversampling factor $f$ (which determines the sensitivity with respect to the minimum detectable displacement) is related to the phenomenon under observation and the product resolution. As far as glaciers are concerned, a resolution in the order of a few meters is fit-for-purpose. Therefore, $f$ is set in such way to have a sensitivity ranging from 0.9 to $2.5 \mathrm{~m}$ in both azimuth and range directions. Most of the experiments based on IW SLC images have been performed using an oversampling factor of 8 in azimuth direction and 4 in range direction. As for IW GRDH, $f$ was set to 8 in both azimuth and range directions. Finally, the value for $f$ in the case of EW GRDH and EW GRDM images was 16.

As a general guideline, it is a good practice to check the specific pixel spacing for each product as reported in the respective metadata. The use of nominal values, those declared by ESA for a certain product class in the product specification documents (see [3]), in place of the specific ones would bring an error in the estimated displacements. 
Table 1. OT algorithm parameters for the different product classes and test sites.

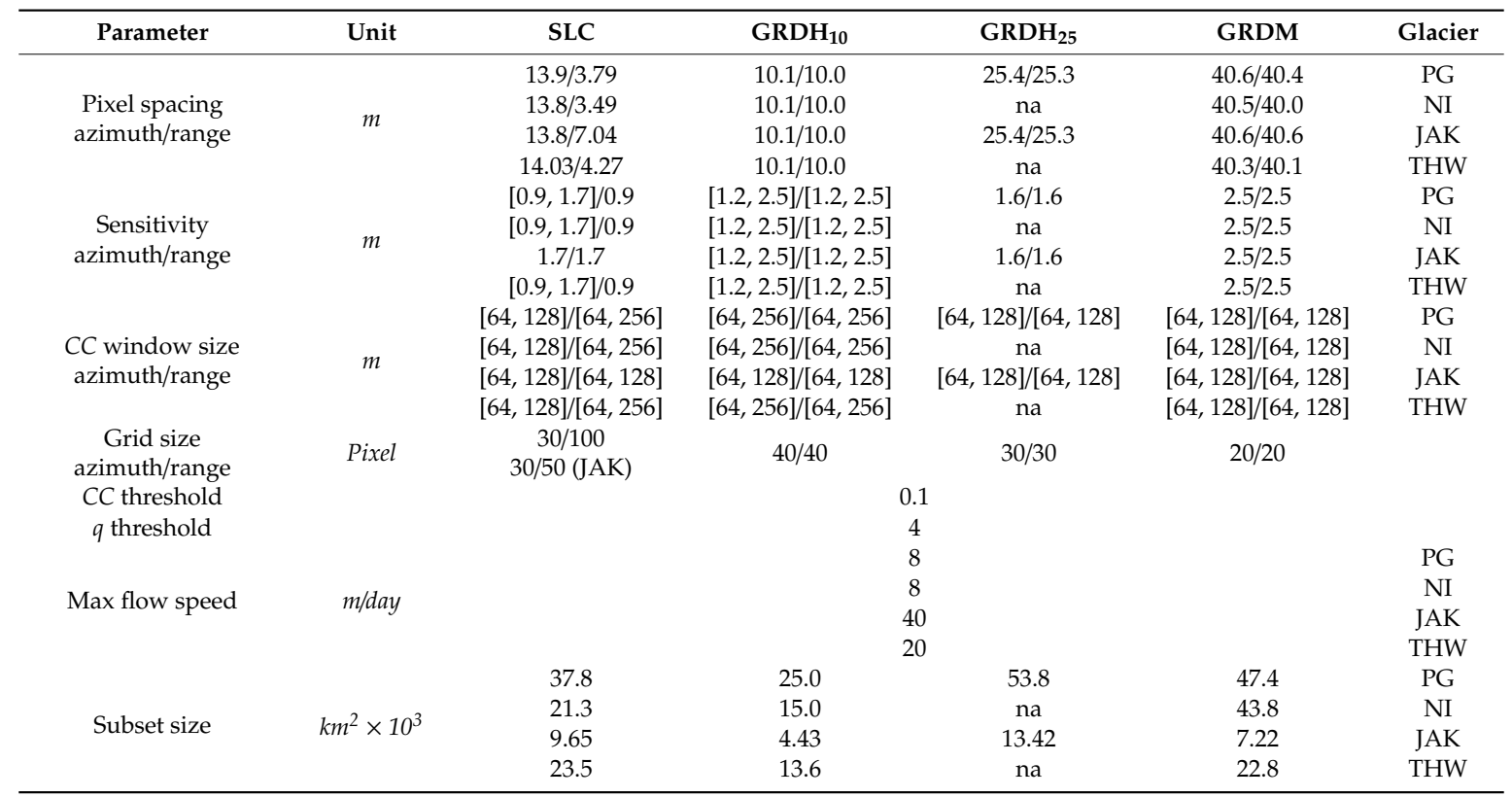

\subsection{Test Areas and Data in Use}

\subsubsection{Petermann Glacier}

The PG flows within the Hall Basin in the Nares Strait in Northwestern Greenland, constituting one of the largest glaciers of the region. It drains ice from the center of the Greenland ice sheet to the ocean through the Petermann Fjord, which is approximately $90 \mathrm{~km}$ long. The thickness of the ice shelf is higher than $100 \mathrm{~m}$, while its width is of approximately $15 \mathrm{~km}$. This glacier is characterized by low resistive stresses along flow because of the limited cohesion with the fjord walls [42]. It flows like a river towards the sea with a velocity of approximately $1.1 \mathrm{~km} / \mathrm{year}$ at its grounding line since the 1990s [43,44], delivering annually 12 tons of ice into the ocean [42].

\subsubsection{Nioghalvfjerdsfjorden}

NI is located in the Northeastern part of the Greenland, of which it represents the largest ice shelf. Its length and width at mid-distance measure more than $70 \mathrm{~km}$ and approximately $20 \mathrm{~km}$, respectively. Together with the adjacent Zachariæ Isstrøm and Storstrømmen, it drains more than the $10 \%$ of the Greenland ice sheet [45]. Potentially, this region alone could rise the global sea level of more than one meter in the unlikely event of complete loss of the ice sheet [46]. The maximum velocities for NI, in the order of $5 \mathrm{~m} /$ day, are found near the grounding line and have been quite stable in recent years [47].

\subsubsection{Jackobshavn Isbræ}

JAK is located in the Western part of Greenland and is the fastest glacier draining the ice sheet [48]. During the late 1990s, the ice tongue was involved in several break-up events causing the glacier to increase its velocity. This phenomenon continued until recent years [49] and is influenced by the warming of the water in the adjacent ocean [50]. The literature pointed out that this glacier is subject to high velocity variability over the time [51]. Nowadays its peak velocity is, on average, more than $20 \mathrm{~m} /$ day [47].

\subsubsection{Thwaites Glacier}

THW is an extremely large and fast-moving Antarctic glacier flowing into Pine Island Bay. As highlighted in [52], it is contributing to the global sea level rise for about one millimeter per year. 
The THW has a wide ice front (about $120 \mathrm{~km}$ long), and its ice flow speed increased, in its lower part, from 50 to $100 \mathrm{~m} /$ year since 2009 [52]. Authors of recent studies believe that the THW has the greatest potential for further near-term increases in ice flux, thus causing a rapid sea-level rise [53].

\subsubsection{Data}

The datasets used in this study have been acquired by the S1 constellation in 2017. For each test site and for each product class (when available), 24 images organized in 12 pairs (approximately a couple per month) have been analyzed for displacement estimation using OT. Overall, 168 couples have been considered. In the case of the PG and JAK, all the product classes (IW SLC, IW GRDH, EW GRDH, and EW GRDM) were available in the SDH. In the case of NI and THW, the EW GRDH product class was not accessible, therefore the processing for EW acquisitions was limited to GRDM products.

Reference data for glaciers displacements along selected transects were provided in [47]. They were retrieved using the OT algorithm implemented in the GAMMA-SAR software suite [54] and applied to couples of S1 SLC images [54]. As declared by the authors, the spatial resolution of the output velocity maps is of $388 \mathrm{~m}$ in ground range and $320 \mathrm{~m}$ in azimuth. After post-processing and filtering, the final product was resampled on a $100 \mathrm{~m} \times 100 \mathrm{~m}$ cartographic grid [47] representing the source of information used in this study in the assessment phase. The number of sampling points for the considered transects are the same as in [47]. Their values are: PG-900 along flow, 1107 across flow; NI—800 along flow, 736 across flow; JAK—900 along flow, 699 across flow; THW-1800 along flow, 2135 across flow.

In Table 2, the monthly average flow velocity across the selected transects for the four considered glaciers as extracted from the reference literature [47] is reported. The PG shows a quite uniform behavior all over the year, with exceptions in the months of July (for both along and across flows), and August (across flow only).

Table 2. Monthly average flow velocities for the four considered glaciers extracted from the reference literature [47]. Values are expressed in m/day.

\begin{tabular}{ccccccccc}
\hline \multirow{2}{*}{ Time } & \multicolumn{2}{c}{ PG } & \multicolumn{2}{c}{ NI } & \multicolumn{2}{c}{ JAK } & \multicolumn{2}{c}{ THW } \\
\cline { 2 - 9 } & Along & Across & Along & Across & Along & Across & Along & Across \\
\hline January & 2.49 & 2.95 & 1.94 & 2.86 & 10.6 & 3.45 & 9.64 & 4.75 \\
February & 2.58 & 2.86 & 1.92 & 2.87 & 9.76 & 3.26 & 9.88 & 5.62 \\
March & 2.57 & 2.87 & 1.93 & 2.90 & 9.71 & 3.30 & 9.86 & 5.26 \\
April & 2.45 & 2.91 & 1.88 & 2.88 & 9.26 & 3.29 & 9.75 & 4.87 \\
May & 2.47 & 2.97 & 1.92 & 2.87 & 10.3 & 2.47 & 9.68 & 5.07 \\
June & 2.60 & 2.99 & 1.89 & 3.04 & 12.3 & 3.17 & 9.64 & 5.20 \\
July & 3.56 & 3.22 & 3.16 & 3.12 & 8.80 & 3.48 & 9.67 & 5.05 \\
August & 2.87 & 3.21 & 1.97 & 3.08 & 13.0 & 3.54 & 9.08 & 5.09 \\
September & 2.69 & 2.96 & 1.90 & 2.99 & 11.0 & 3.25 & 9.08 & 4.68 \\
October & 2.73 & 2.90 & 1.94 & 2.90 & 10.4 & 3.25 & 9.39 & 4.68 \\
November & 2.73 & 2.93 & 1.88 & 2.92 & 10.0 & 3.25 & 9.71 & 4.73 \\
December & 2.72 & 2.93 & 1.93 & 2.91 & 9.65 & 3.24 & 10.3 & 4.75 \\
\hline
\end{tabular}

As for the NI, an abrupt change in the flow velocity (more than one meter per day above the average over the rest of the year) is registered in the month of July for the along flow. As for the across flow, it is more stable, with a slight increase during the summer.

The average monthly flow speed for JAK is more variable. As for the other Greenland glaciers, a speed-up (especially in the along flow direction) is registered during summer, likely due to ice melting effects, with exception made for the month of July, when the flow speed drops at its annual minimum.

As regards the THW, as reported in the last column of Table 2, the flow speed is almost uniform all over the year, i.e., there are no remarkable seasonal effects in the glacier behavior. 


\section{Results}

The CC window dimension is determined by a trade-off between different needs. First, it must be large enough to estimate the maximum expected displacement, since the maximum detectable one (in pixel units) is equal to half the size of the correlation window. Large windows can affect the preservation of the edges of the features of interest [55], present a higher likelihood of including changing areas (thus causing a drop in the correlation peak) and tend to increase the computational load. In the literature, some techniques are proposed for a feature-based selection of the CC window size (see [56] as an example) but, in most of the cases, the simplest and safest way to operate is with a trial-and-error application-oriented approach. Conversely, it is known that, if the correlation window size is too small, the signal-to-noise ratio is low and this leads to a noisy estimate of the shifts between the master and slave patches [57]. The tests performed revealed that the minimum window dimension allowing for reliable results is $64 \times 64$ square pixel. As explained in the following, different windows have been tested in order to find the best match between the displacements estimated through the implemented OT and those available from past literature.

For a GCP to qualify as a good candidate, the quality parameters $c_{\max }$ and $q$ need to be greater than empirically pre-determined thresholds. In this study the threshold value for $c_{\max }$ has been set to 0.1 which is in line with similar choices in literature (as an example, in Reference [40] a threshold of 0.2 was suggested). However, in order to enforce the requirements for valid GCPs, both the conditions on the maximum correlation and on the ratio with respect to the background, here estimated to be at least 4, have been imposed.

\subsection{Comparison with Literature Data}

First, the results of the implemented OT algorithm were compared with available literature data provided in [47] and relevant to selected transects in along flow and across flow directions. A graphic overview of the four test sites and of the corresponding analyzed transects (AA —along flow, BB-across flow) is provided in Figure $2 \mathrm{a}-\mathrm{d}$ for the PG, NI, JAK and THW, respectively. Greenland data have been geocoded using a polar stereographic projection with origin latitude of 70 decimal degrees and origin longitude of -45 decimal degrees. As for Antarctica data, the origin latitude was of -71 decimal degrees and the origin longitude of 0 decimal degrees.

Data reported in the subsequent tables represent the root mean square error (RMSE) of the estimated flow velocities against reference data calculated as follows:

$$
\operatorname{RMSE}=\sqrt{\sum_{i=1}^{N} \frac{\left(\hat{v}_{i}-v_{i}\right)^{2}}{N}}
$$

where $\hat{v}_{i}$ is the estimated flow speed (expressed in $\mathrm{m} /$ day) and $v_{i}$ is reference flow speed for a given point $i$ along one of the considered transects.

\subsubsection{Petermann Glacier}

In Tables 3-5, the results obtained on the PG for the IW SLC, IW GRDH, and EW GRDH and EW GRDM product classes, are shown respectively. Each table entry represents the root mean square error (RMSE), expressed in meters per day, against reference data along the along flow and across flow transects introduced above. Boxes with grey shading indicate the best performance with respect to the considered literature data, while those with orange shading indicate the same result achieved with a higher computational time. Each column corresponds to a selected combination of the CC window size and of the oversampling factor, both declared on the top of the column ( $w$ stands for the dimension of the CC window and $f$ for the oversampling factor). When only one value for these two parameters is present, it refers to both azimuth and slant range directions. Two numbers separated by the slash character means that an asymmetric CC window and/or oversampling factor has been used 
for running that particular experiment. This notation is kept for all the subsequent tables reporting the results of the experiments concerning the other analyzed glaciers.

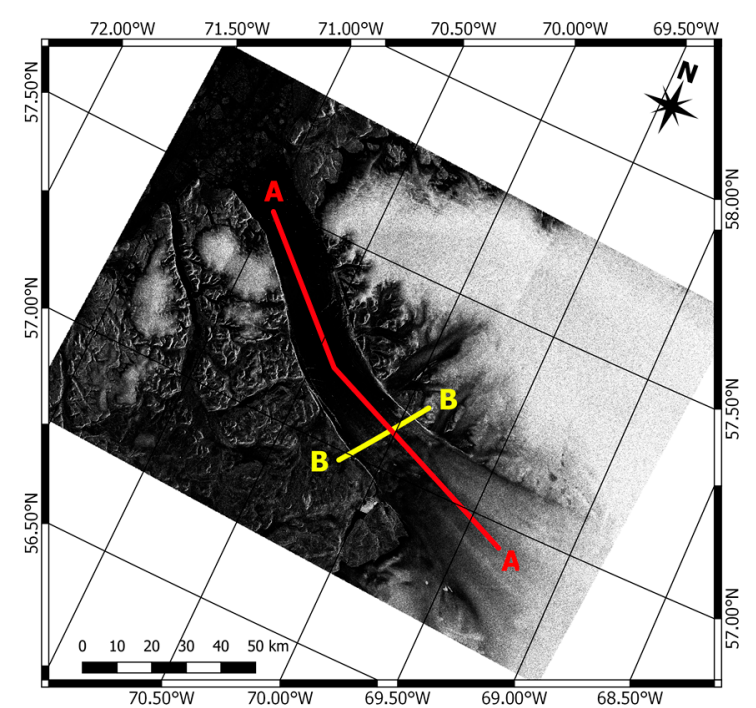

(a)

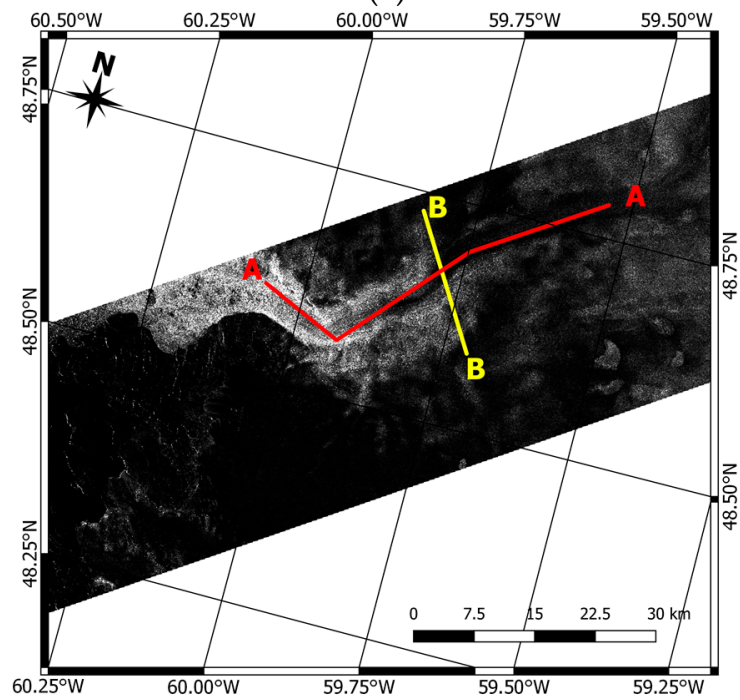

(c)

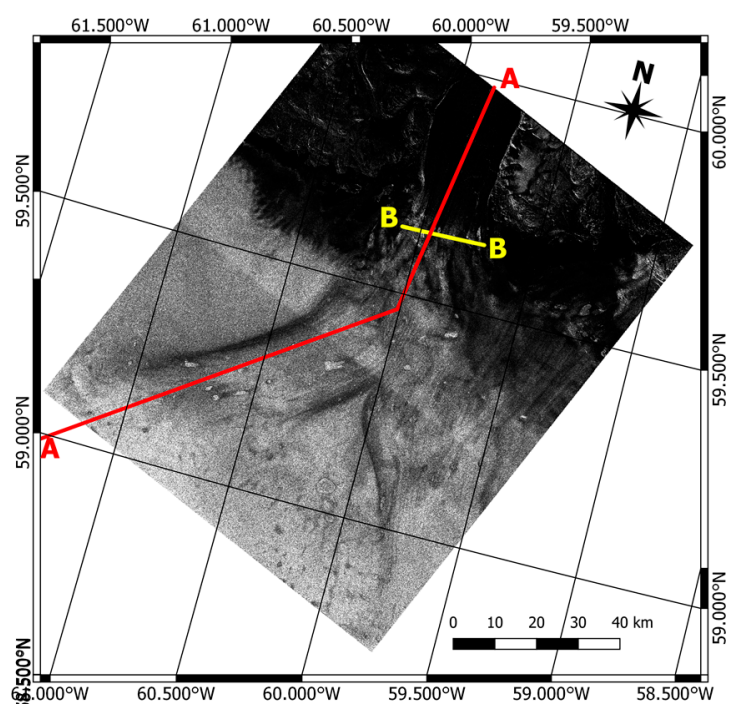

(b)

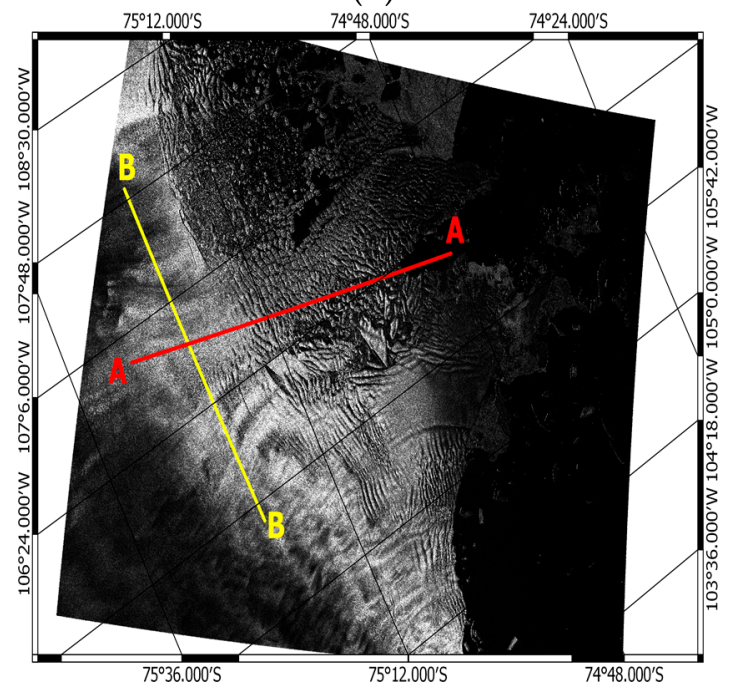

(d)

Figure 2. SAR images (all acquired in right ascending orbit) of the test sites with the corresponding analyzed transects (AA—along flow, BB-across flow). (a) Petermann glacier, (b) Nioghalvfjerdsfjorden, (c) Jakobshavn Isbræ and (d) Thwaites glacier.

From the results we can see that, for IW products, the change in the window size does not influence significantly the performance with respect to reference data which shows, in most cases, a discrepancy of less than $20 \mathrm{~cm}$ per day, with a peak of $0.86 \mathrm{~m} /$ day for the pair 11-17 June using GRDH data. The most significant effect is that of the CC window size on the computational time. Especially for GRDH images, an increase in the dimension of the CC window has a negative impact on it, with negligible variations of the estimated flow speed.

In Figure $3 a-d$, an example of the results obtained running the OT algorithm, respectively on PG IW SLC, IW GRDH, EW GRDH and EW GRDM images, is shown. Examples of the quality parameter maps, i.e., maximum CC and $q$, are reported in Figure $4 a, b$, respectively. Only the IW SLC case is shown for brevity. 
Table 3. PG, IW SLC product class experiments, RMSE (expressed in m/day) with respect to available literature data measured along selected along flow and across flow transects.

\begin{tabular}{|c|c|c|c|c|c|c|c|c|c|}
\hline \multicolumn{10}{|c|}{ Petermann-IW SLC } \\
\hline \multirow{2}{*}{ Observation } & \multirow{2}{*}{ Track } & \multicolumn{2}{|c|}{$w=64, f=16 / 4$} & \multicolumn{2}{|c|}{$w=64 / 128, f=8 / 4$} & \multicolumn{2}{|c|}{$w=128, f=8 / 4$} & \multicolumn{2}{|c|}{$w=64 / 256, f=8 / 4$} \\
\hline & & Along & Across & Along & Across & Along & Across & Along & Across \\
\hline 6-12 Jan & $26 \mathrm{AA}$ & 0.14 & 0.10 & 0.14 & 0.14 & 0.14 & 0.17 & 0.10 & 0.14 \\
\hline 11-17 Feb & $26 \mathrm{DD}$ & 0.30 & 0.26 & 0.28 & 0.28 & 0.28 & 0.28 & 0.28 & 0.26 \\
\hline 1-7 Mar & $26 \mathrm{DD}$ & 0.14 & 0.14 & 0.14 & 0.14 & 0.10 & 0.14 & 0.10 & 0.14 \\
\hline 6-12 Apr & $26 \mathrm{DD}$ & 0.20 & 0.14 & 0.22 & 0.14 & 0.22 & 0.14 & 0.20 & 0.14 \\
\hline 18-24 May & $26 \mathrm{DD}$ & 0.17 & 0.10 & 0.14 & 0.17 & 0.17 & 0.14 & 0.14 & 0.14 \\
\hline 11-17 Jun & $26 \mathrm{DD}$ & 0.14 & 0.10 & 0.28 & 0.24 & 0.17 & 0.35 & 0.20 & 0.28 \\
\hline 11-17 Aug & $26 \mathrm{DD}$ & 0.20 & 0.26 & 0.20 & 0.35 & 0.17 & 0.28 & 0.17 & 0.33 \\
\hline 10-16 Aug & $26 \mathrm{DD}$ & 0.26 & 0.45 & 0.22 & 0.45 & 0.22 & 0.44 & 0.24 & 0.35 \\
\hline 9-15 Sep & $26 \mathrm{DD}$ & 0.10 & 0.10 & 0.10 & 0.10 & 0.00 & 0.10 & 0.10 & 0.10 \\
\hline 9-15 Oct & $26 \mathrm{DD}$ & 0.14 & 0.17 & 0.14 & 0.17 & 0.14 & 0.17 & 0.14 & 0.17 \\
\hline 8-14 Nov & $26 \mathrm{DD}$ & 0.10 & 0.14 & 0.10 & 0.17 & 0.14 & 0.20 & 0.10 & 0.17 \\
\hline 8-14 Dec & $26 \mathrm{DD}$ & 0.24 & 0.32 & 0.26 & 0.35 & 0.24 & 0.35 & 0.26 & 0.36 \\
\hline Time & & \multicolumn{2}{|c|}{$\approx 1.5 \mathrm{~h}$} & \multicolumn{2}{|c|}{$\approx 1.7 \mathrm{~h}$} & \multicolumn{2}{|c|}{$\approx 3.5 \mathrm{~h}$} & \multicolumn{2}{|c|}{$\approx 4 \mathrm{~h}$} \\
\hline
\end{tabular}

Table 4. PG, IW GRDH product class experiments, RMSE (expressed in $\mathrm{m} /$ day) with respect to available literature data measured along selected along flow and across flow transects.

\begin{tabular}{|c|c|c|c|c|c|c|c|}
\hline \multicolumn{8}{|c|}{ Petermann-IW GRDH } \\
\hline \multirow{2}{*}{ Observation } & \multirow{2}{*}{ Track } & \multicolumn{2}{|c|}{$w=64, f=8$} & \multicolumn{2}{|c|}{$w=128, f=8$} & \multicolumn{2}{|c|}{$w=256, f=4$} \\
\hline & & Along & Across & Along & Across & Along & Across \\
\hline 6-12 Jan & $26 \mathrm{AA}$ & 0.17 & 0.24 & 0.14 & 0.17 & 0.14 & 0.32 \\
\hline 11-17 Feb & $26 \mathrm{DD}$ & 0.28 & 0.26 & 0.24 & 0.24 & 0.22 & 0.33 \\
\hline 1-7 Mar & $26 \mathrm{DD}$ & 0.26 & 0.24 & 0.24 & 0.22 & 0.22 & 0.30 \\
\hline 6-12 Apr & $26 \mathrm{DD}$ & 0.28 & 0.28 & 0.24 & 0.28 & 0.22 & 0.48 \\
\hline 18-24 May & $26 \mathrm{DD}$ & 0.28 & 0.32 & 0.26 & 0.30 & 0.17 & 0.45 \\
\hline 11-17 Jun & $26 \mathrm{DD}$ & 0.87 & 0.48 & 0.28 & 0.47 & 0.32 & 0.46 \\
\hline 11-17 Aug & $26 \mathrm{DD}$ & 0.36 & 0.32 & 0.32 & 0.28 & 0.28 & 0.37 \\
\hline 10-16 Aug & $26 \mathrm{DD}$ & 0.24 & 0.24 & 0.22 & 0.20 & 0.20 & 0.30 \\
\hline 9-15 Sep & $26 \mathrm{DD}$ & 0.17 & 0.17 & 0.17 & 0.28 & 0.42 & 0.30 \\
\hline 9-15 Oct & $26 \mathrm{DD}$ & 0.17 & 0.28 & 0.10 & 0.17 & 0.10 & 0.41 \\
\hline 8-14 Nov & $26 \mathrm{DD}$ & 0.24 & 0.20 & 0.24 & 0.20 & 0.14 & 0.33 \\
\hline 8-14 Dec & $26 \mathrm{DD}$ & 0.33 & 0.22 & 0.33 & 0.22 & 0.26 & 0.37 \\
\hline Time & & \multicolumn{2}{|c|}{$\approx 1 \mathrm{~h}$} & \multicolumn{2}{|c|}{$\approx 7.5 \mathrm{~h}$} & \multicolumn{2}{|c|}{$\approx 8.8 \mathrm{~h}$} \\
\hline
\end{tabular}

Table 5. PG, EW GRDH and EW GRDM product classes experiments, RMSE (expressed in m/day) with respect to available literature data measured along selected along flow and across flow transects.

\begin{tabular}{|c|c|c|c|c|c|c|c|c|c|}
\hline \multirow{3}{*}{ Observation } & \multirow{3}{*}{ Track } & \multicolumn{4}{|c|}{ Petermann-EW GRDH } & \multicolumn{4}{|c|}{ Petermann-EW GRDM } \\
\hline & & \multicolumn{2}{|c|}{$w=64, f=16$} & \multicolumn{2}{|c|}{$w=128, f=16$} & \multicolumn{2}{|c|}{$w=64, f=16$} & \multicolumn{2}{|c|}{$w=128, f=16$} \\
\hline & & Along & Across & Along & Across & Along & Across & Along & Across \\
\hline 1-7 Jan & $41 \mathrm{AA}$ & na & na & na & na & na & na & na & na \\
\hline $12-18$ Feb & $41 \mathrm{DD}$ & na & na & na & na & na & na & na & na \\
\hline 8-1 Apr & $41 \mathrm{AA}$ & na & na & na & na & na & na & na & na \\
\hline 1-13 Apr & $41 \mathrm{AA}$ & 0.47 & 0.46 & 0.42 & 0.75 & 0.69 & 0.66 & 0.67 & 1.02 \\
\hline 7-19 May & $41 \mathrm{AA}$ & 0.45 & 0.62 & 0.44 & 0.62 & 0.67 & 0.91 & 0.73 & 1.17 \\
\hline 10-22 Jun & $41 \mathrm{AA}$ & na & na & 0.35 & 0.68 & 0.61 & 0.98 & 0.57 & 1.21 \\
\hline 6-18 Jul & $41 \mathrm{AA}$ & 0.88 & 0.82 & 0.62 & 0.68 & 0.49 & 0.68 & 0.75 & 1.07 \\
\hline 11-23 Aug & $41 \mathrm{AA}$ & 0.50 & 0.59 & 0.37 & 0.63 & 0.48 & 0.59 & 0.69 & 1.10 \\
\hline 4-16 Sep & $41 \mathrm{AA}$ & 0.36 & 0.40 & 0.32 & 0.41 & 0.62 & 0.94 & 0.60 & 1.14 \\
\hline $10-22$ Oct & $41 \mathrm{AA}$ & 0.48 & 0.52 & 0.36 & 0.69 & 0.70 & 0.81 & 0.48 & 1.10 \\
\hline 3-15 Nov & $41 \mathrm{AA}$ & 0.33 & 0.35 & 0.35 & 0.45 & 0.71 & 0.71 & 0.42 & 1.07 \\
\hline 9-21 Dec & $41 \mathrm{AA}$ & 0.33 & 0.41 & 0.33 & 0.66 & 0.33 & 0.63 & 0.22 & 1.04 \\
\hline Time & & \multicolumn{2}{|c|}{$\approx 0.8 \mathrm{~h}$} & \multicolumn{2}{|c|}{$\approx 22.4 \mathrm{~h}$} & \multicolumn{2}{|c|}{$\approx 1.7 \mathrm{~h}$} & \multicolumn{2}{|c|}{$\approx 15.6 \mathrm{~h}$} \\
\hline
\end{tabular}




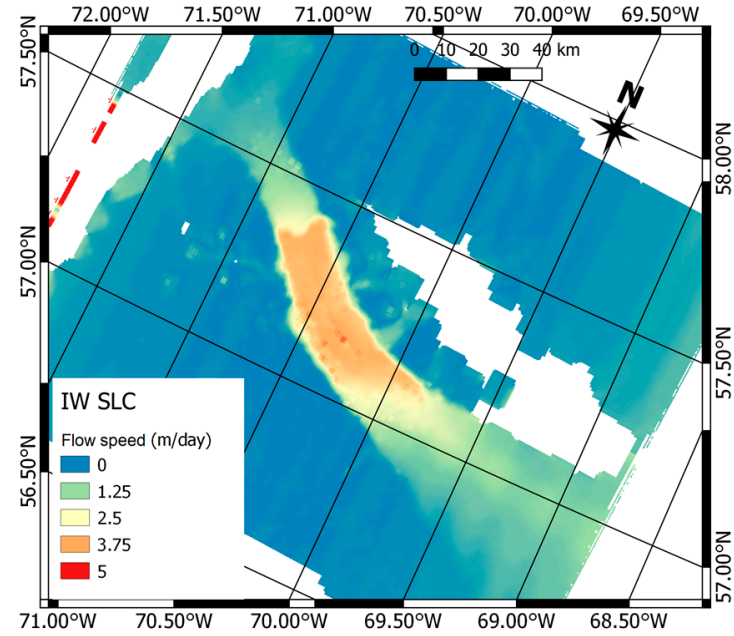

(a)

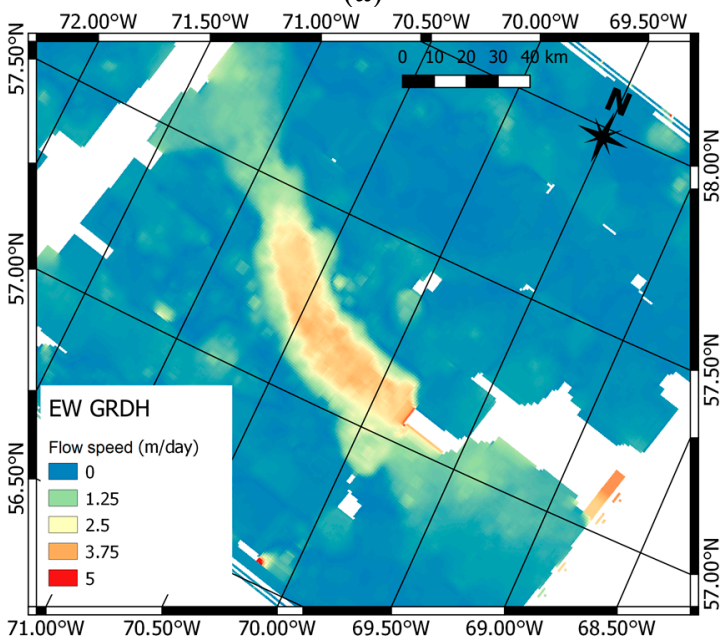

(c)

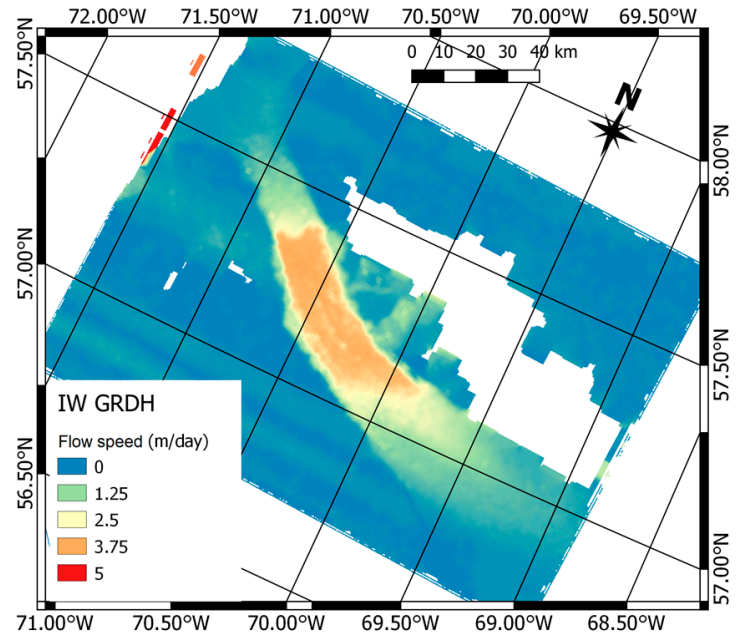

(b)

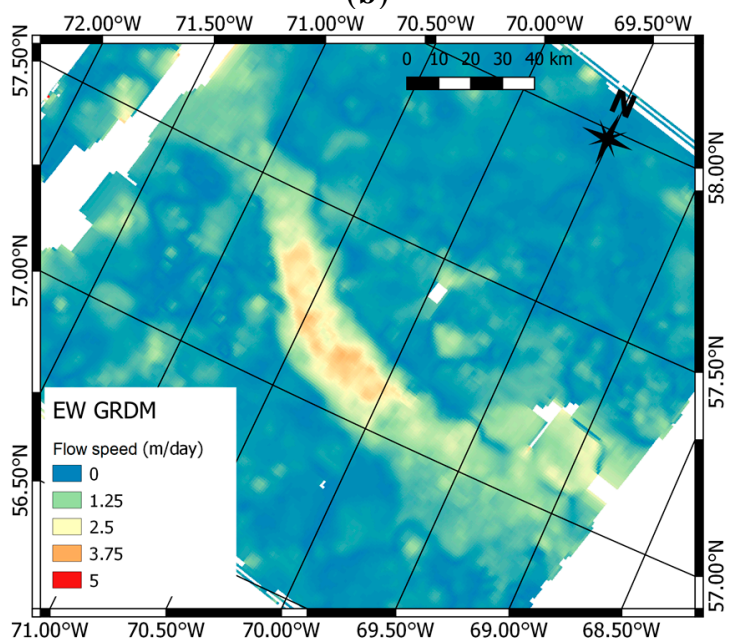

(d)

Figure 3. PG, flow speed maps obtained using (a) IW SLC, (b) IW GRDH, (c) EW GRDH and (d) EW GRDM images. Observation periods are 6-12 January 2017 for IW images and 1-13 April for EW images.

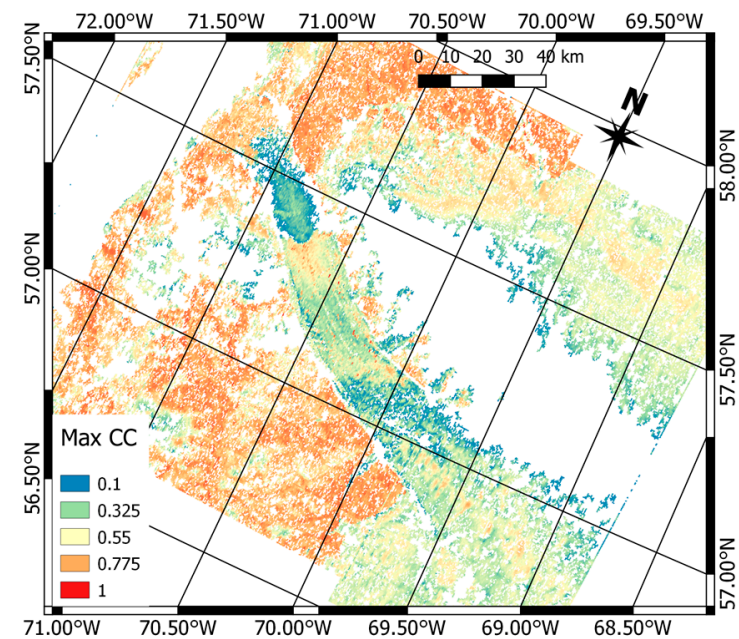

(a)

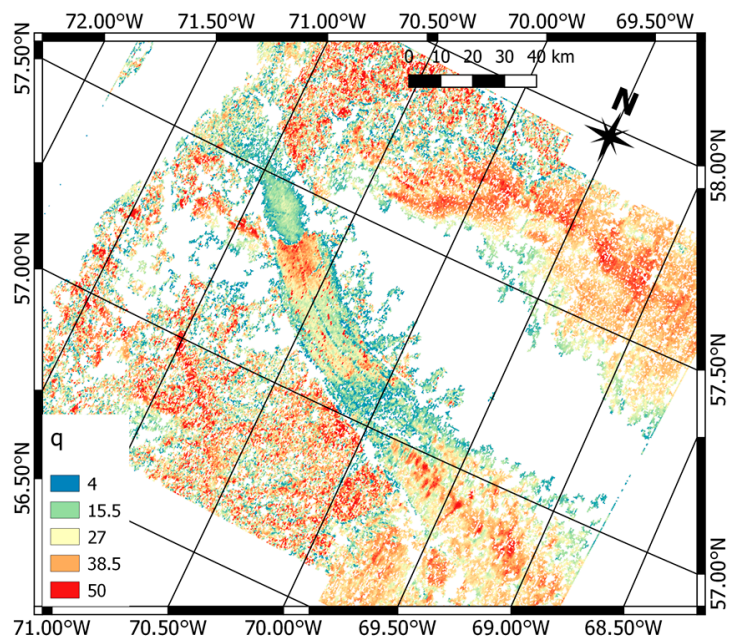

(b)

Figure 4. PG, quality parameters maps obtained by processing the IW SLC pair 6-12 January 2017. (a) Maximum correlation. (b) Ratio between the peak and the background of the correlation matrix (q-parameter). 
Qualitatively, the flow speed maps obtained by processing IW products are quite similar. In both cases, the velocity fields are very homogeneous outside the glacier area, where they are expected to be almost null. Within it, there are no significant differences in the delineation of edges and features due to the resolution change of the input product.

Considering the maps obtained by processing EW images, it is evident that, in both cases, the lower resolution of the input product causes a blurring and a fragmentation of the estimated velocity field. Outside the glacier area, many regions exhibiting non-null velocity appear. Inside the glacier, the estimated velocity field tends to be flatter and the edges less defined. This effect is more pronounced when using GRDM images.

The correlation map depicted in Figure 4a exhibits acceptable values all over the glacier, with no significant presence of rejected GCPs which are mainly concentrated at the North edge of the glacier. As a general comment, the correlation resulted higher south of the glacier, in areas where the ice melted and, consequently, the bare land got exposed. Similar considerations hold for the $q$ parameter and, overall, for the quality parameters of the GRDH experiments (not shown for brevity) and this supports the similarity of the outputs.

In Figure 5, the difference map (expressed in m/day) between the estimated velocity field and reference data for the observation period 6-12 January 2017 is shown. In particular, Figure 5a is relevant to SLC image input, while Figure 5b concerns to the IW GRDH experiment. Reference data in form of map are available only for the central part of the glacier, therefore these pictures refer to a subset of the whole study area. Data concerning EW GRDH and EW GRDM are not displayed for brevity. As explained before, they are affected by the lower resolution of the input products, which shows significant differences with respect to reference data, especially at the edges of the glacier.

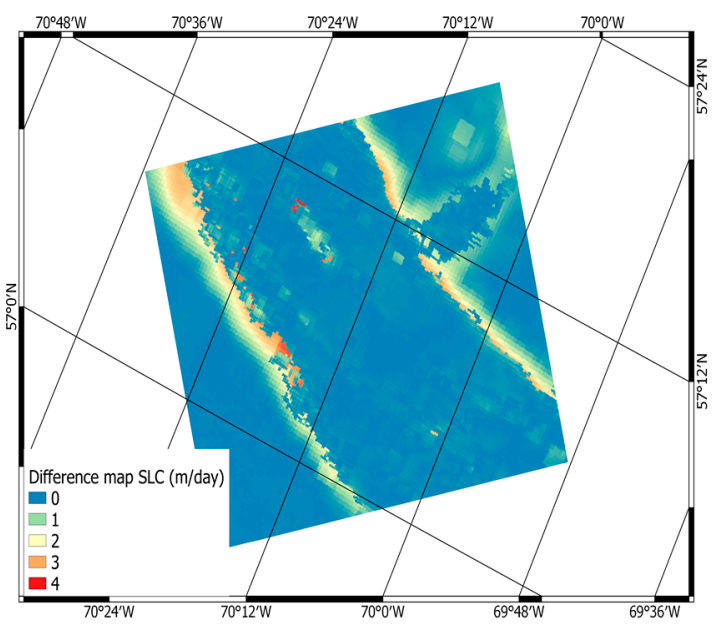

(a)

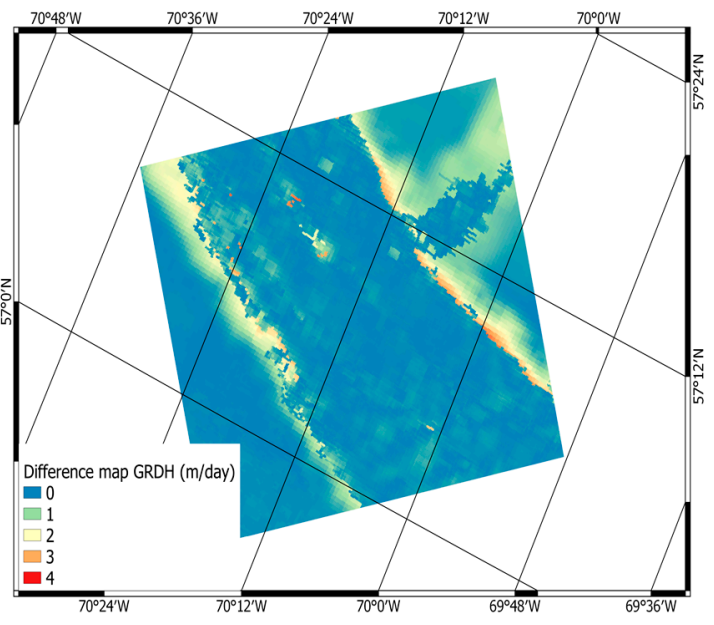

(b)

Figure 5. PG, velocity difference map relevant to the observation period 6-12 January 2017 between the implemented frequency domain OT and reference data for (a) SLC and (b) GRDH image input.

In both cases, very small differences can be appreciated in the two velocity fields, in particular within the glacier area, where the maps show almost null differences. The higher values characterize the edges of the glacier. This can be partially due to both the diverse windowing used by the two different algorithms for the calculation of the CC and the resampling necessary to overlap the different maps. Another area exhibiting moderate discrepancies is at the right-hand side of the glacier, where it forms a sort of branch. Here, the differences are slightly more pronounced when using IW GRDH images. 


\subsubsection{Nioghalvfjerdsfjorden}

Results concerning the NI are shown in Tables 6 and 7 respectively for the IW SLC and GRDH product classes. Those concerning EW GRDH images are omitted for brevity but will be discussed afterwards together with aggregated data for all of the performed experiments.

Table 6. NI, IW SLC product class experiments, RMSE (expressed in $\mathrm{m} /$ day) with respect to available literature data measured along selected along/across flow transects.

\begin{tabular}{|c|c|c|c|c|c|c|c|c|c|}
\hline \multicolumn{10}{|c|}{ Nioghalvifierdsfjorden-IW SLC } \\
\hline \multirow{2}{*}{ Observation } & \multirow{2}{*}{ Track } & \multicolumn{2}{|c|}{$w=64, f=16 / 4$} & \multicolumn{2}{|c|}{$w=64 / 128, f=8 / 4$} & \multicolumn{2}{|c|}{$w=128, f=8 / 4$} & \multicolumn{2}{|c|}{$w=256, f=8 / 4$} \\
\hline & & Along & Across & Along & Across & Along & Across & Along & Across \\
\hline 3-9 Jan & $74 \mathrm{AA}$ & 0.36 & 0.47 & 0.33 & 0.32 & 0.33 & 0.39 & 0.33 & 0.44 \\
\hline 2-8 Feb & $74 \mathrm{AA}$ & 0.24 & 0.20 & 0.30 & 0.26 & 0.30 & 0.24 & 0.30 & 0.30 \\
\hline 4-10 Mar & $74 \mathrm{AA}$ & 0.28 & 0.26 & 0.47 & 0.45 & 0.45 & 0.47 & 0.37 & 0.41 \\
\hline 15-21 Apr & $74 \mathrm{AA}$ & 0.14 & 0.22 & 0.10 & 0.22 & 0.10 & 0.24 & 0.10 & 0.30 \\
\hline 3-9 May & $74 \mathrm{AA}$ & 0.28 & 0.41 & 0.42 & 0.40 & 0.37 & 0.45 & 0.39 & 0.52 \\
\hline 2-8 Jun & $74 \mathrm{AA}$ & 0.52 & 0.59 & 0.70 & 0.66 & 0.49 & 0.48 & 0.49 & 0.53 \\
\hline $2-8 \mathrm{Jul}$ & $74 \mathrm{AA}$ & 0.28 & 0.53 & 1.05 & 1.02 & 0.22 & 0.37 & 0.22 & 0.42 \\
\hline 1-7 Aug & $74 \mathrm{AA}$ & 0.42 & 0.40 & 1.35 & 1.04 & 0.24 & 0.37 & 0.26 & 0.40 \\
\hline 6-12 Sep & $74 \mathrm{AA}$ & 0.33 & 0.32 & 0.32 & 0.33 & 0.28 & 0.20 & 0.56 & 0.28 \\
\hline $6-12$ Oct & $74 \mathrm{AA}$ & 0.14 & 0.20 & 0.14 & 0.30 & 0.10 & 0.14 & 0.14 & 0.20 \\
\hline 5-11 Nov & $74 \mathrm{AA}$ & 0.14 & 0.17 & 0.20 & 0.50 & 0.10 & 0.20 & 0.14 & 0.26 \\
\hline 5-11 Dec & $74 \mathrm{AA}$ & 0.14 & 0.22 & 0.22 & 0.17 & 0.22 & 0.20 & 0.22 & 0.17 \\
\hline Time & & \multicolumn{2}{|c|}{$\approx 1 \mathrm{~h}$} & \multicolumn{2}{|c|}{$\approx 1.4 \mathrm{~h}$} & \multicolumn{2}{|c|}{$\approx 2.8 \mathrm{~h}$} & \multicolumn{2}{|c|}{$\approx 15.8 \mathrm{~h}$} \\
\hline
\end{tabular}

Table 7. NI, IW GRDH product class experiments, RMSE (expressed in m/day) with respect to available literature data measured along selected along/across flow transects.

\begin{tabular}{|c|c|c|c|c|c|c|c|}
\hline \multicolumn{8}{|c|}{ Nioghalvifierdsfjorden-IW GRDH } \\
\hline \multirow{2}{*}{ Observation } & \multirow{2}{*}{ Track } & \multicolumn{2}{|c|}{$w=64, f=8$} & \multicolumn{2}{|c|}{$w=128, f=8$} & \multicolumn{2}{|c|}{$w=256, f=4$} \\
\hline & & Along & Across & Along & Across & Along & Across \\
\hline 3-9 Jan & $74 \mathrm{AA}$ & 0.24 & 0.33 & 0.22 & 0.32 & 0.17 & 0.26 \\
\hline 2-8 Feb & $74 \mathrm{AA}$ & 0.35 & 0.54 & 0.32 & 0.57 & 0.28 & 0.47 \\
\hline 4-10 Mar & $74 \mathrm{AA}$ & 0.30 & 0.56 & 0.24 & 0.52 & 0.22 & 0.45 \\
\hline 15-21 Apr & $74 \mathrm{AA}$ & 0.28 & 0.48 & 0.24 & 0.48 & 0.20 & 0.42 \\
\hline 3-9 May & $74 \mathrm{AA}$ & 0.24 & 0.33 & 0.24 & 0.33 & 0.24 & 0.39 \\
\hline $2-8$ Jun & $74 \mathrm{AA}$ & 0.30 & 0.40 & 0.30 & 0.41 & 0.33 & 0.47 \\
\hline 2-8 Jul & $74 \mathrm{AA}$ & 0.17 & 0.24 & 0.20 & 0.26 & 0.14 & 0.28 \\
\hline 1-7 Aug & $74 \mathrm{AA}$ & 0.20 & 0.44 & 0.14 & 0.30 & 0.20 & 0.37 \\
\hline 6-12 Sep & $74 \mathrm{AA}$ & 0.61 & 0.50 & 0.32 & 0.24 & 0.63 & 0.22 \\
\hline $6-12$ Oct & $74 \mathrm{AA}$ & 0.14 & 0.22 & 0.10 & 0.20 & 0.26 & 0.35 \\
\hline 5-11 Nov & $74 \mathrm{AA}$ & 0.10 & 0.10 & 0.10 & 0.36 & 0.22 & 0.36 \\
\hline 5-11 Dec & $74 \mathrm{AA}$ & 0.10 & 0.24 & 0.10 & 0.24 & 0.20 & 0.33 \\
\hline Time & & \multicolumn{2}{|c|}{$\approx 0.7 \mathrm{~h}$} & \multicolumn{2}{|c|}{$\approx 4.5 \mathrm{~h}$} & \multicolumn{2}{|c|}{$\approx 5.3 \mathrm{~h}$} \\
\hline
\end{tabular}

As for the PG, the flow velocities estimated using the EW GRDH product class are highly affected by the lower resolution. As better explained below, the RMSE with respect to reference data is significant especially in the across flow direction, for which it is close to one meter per day.

Overall, the results are similar to those discussed above for the PG. Even in this case, the performance of IW SLC and IW GRDH products are fully comparable against the reference literature. Using SLC images, the higher values of the RMSE tend to occur during the summer when, as reported in Table 2, the flow velocity is higher. The increase in the CC window size results in a more stable RMSE, at the expense of computational times. Conversely, IW GRDH results are not significantly affected by seasonal effects. 


\subsubsection{Jackobshavn Isbræ}

The results concerning JAK are reported in Tables 8 and 9 for the processed IW SLC and IW GRDH images, respectively. Based on literature data, during 2017 this glacier reached peak velocities of more than $30 \mathrm{~m} /$ day [47]. Therefore, over an observation period of 6 days, displacements in the order of $200 \mathrm{~m}$ are expected. Using SLC images with range pixel spacing in the order of $3.5 \mathrm{~m}$, the range window size of 64 or 128 pixels is not enough to detect this order of displacements. Moreover, the use of windows of 256 pixels in range direction (or bigger) leads to wide decorrelation areas preventing a reliable estimate of the displacements. Therefore, for this glacier, a multilook factor of two in range direction was applied to SLC products. Being an incoherent mean [4], multilooking increased the range pixel spacing of input products to approximately $7 \mathrm{~m}$ (see Table 1) allowing, consequently, the adoption of smaller CC windows.

Table 8. JAK, IW SLC product class experiments, RMSE (expressed in $\mathrm{m} /$ day) with respect to available literature data measured along selected along/across flow transects.

\begin{tabular}{|c|c|c|c|c|c|c|c|c|c|}
\hline \multicolumn{10}{|c|}{ Jackobshavn-IW SLC } \\
\hline \multirow{2}{*}{ Observation } & \multirow{2}{*}{ Track } & \multicolumn{2}{|c|}{$w=64, f=8 / 4$} & \multicolumn{2}{|c|}{$w=64 / 128, f=8 / 4$} & \multicolumn{2}{|c|}{$w=128, f=8 / 4$} & \multicolumn{2}{|c|}{$w=128 / 256, f=8 / 4$} \\
\hline & & Along & Across & Along & Across & Along & Along & Along & Across \\
\hline 4-10 Jan & 90 AA & 1.67 & 0.33 & 1.29 & 0.38 & 1.65 & 0.41 & 2.52 & 0.34 \\
\hline 15-21 Feb & 90 AA & 1.57 & 0.31 & 1.35 & 0.22 & 1.44 & 0.26 & 2.15 & 0.22 \\
\hline 5-11 Mar & 90 AA & 1.55 & 0.26 & 1.56 & 0.24 & 1.57 & 0.26 & 1.97 & 0.28 \\
\hline 4-10 May & 90 AA & 1.45 & 0.86 & 1.08 & 0.30 & 1.30 & 0.28 & 2.43 & 0.30 \\
\hline 3-9 Jun & $90 \mathrm{AA}$ & 1.59 & 0.47 & 1.22 & 0.26 & 1.83 & 0.26 & 2.97 & 0.24 \\
\hline 2-2 Aug & 90 AA & 1.12 & 0.22 & 1.35 & 0.20 & 1.22 & 0.22 & 2.32 & 0.28 \\
\hline 20-26 Aug & 90 AA & 2.25 & 0.65 & 2.39 & 0.20 & 1.40 & 0.26 & 3.40 & 0.24 \\
\hline 13-19 Sep & 90 AA & 1.32 & 0.66 & 1.44 & 0.30 & 1.80 & 0.34 & 4.01 & 0.36 \\
\hline
\end{tabular}

Table 9. JAK, IW GRDH product class experiments, RMSE (expressed in $\mathrm{m} /$ day) with respect to available literature data measured along selected along/across flow transects.

\begin{tabular}{|c|c|c|c|c|c|c|c|c|c|c|c|}
\hline \multicolumn{12}{|c|}{ Jackobshavn-IW GRDH } \\
\hline \multirow{2}{*}{ Observation } & \multirow{2}{*}{ Track } & \multicolumn{2}{|c|}{$w=64, f=8$} & \multicolumn{2}{|c|}{$w=64 / 128, f=8$} & \multicolumn{2}{|c|}{$w=128 / 64, f=8$} & \multicolumn{2}{|c|}{$w=128, f=8$} & \multicolumn{2}{|c|}{$w=256, f=4$} \\
\hline & & Along & Across & Along & Across & Along & Across & Along & Across & Along & Across \\
\hline 4-10 Jan & $90 \mathrm{AA}$ & 1.99 & 0.79 & 2.03 & 0.82 & 1.89 & 0.85 & 1.45 & 0.42 & 3.07 & 0.45 \\
\hline 15-21 Feb & $90 \mathrm{AA}$ & 1.44 & 0.24 & 1.82 & 0.26 & 1.27 & 0.24 & 1.42 & 0.24 & 2.46 & 0.49 \\
\hline 5-11 Mar & $90 \mathrm{AA}$ & 1.57 & 0.53 & 1.76 & 0.32 & 1.35 & 0.35 & 1.43 & 0.32 & 2.24 & 0.55 \\
\hline 4-10 Apr & $90 \mathrm{AA}$ & 1.81 & 0.77 & 1.37 & 0.37 & 1.17 & 0.40 & 1.10 & 0.35 & 1.98 & 0.49 \\
\hline 4-10 May & $90 \mathrm{AA}$ & 1.61 & 0.41 & 1.79 & 0.41 & 1.28 & 0.42 & 1.76 & 0.44 & 3.08 & 0.42 \\
\hline 3-9 Jun & $90 \mathrm{AA}$ & 1.52 & 0.79 & 1.69 & 0.39 & 1.06 & 0.45 & 1.24 & 0.36 & 3.42 & 0.41 \\
\hline 27-2 Aug & $90 \mathrm{AA}$ & 1.66 & 1.10 & 1.09 & 0.57 & 0.85 & 0.37 & 0.89 & 0.33 & 2.47 & 0.45 \\
\hline 20-26 Aug & $90 \mathrm{AA}$ & 1.86 & 0.58 & 1.88 & 0.57 & 1.20 & 0.37 & 1.17 & 0.28 & 2.91 & 0.32 \\
\hline 13-19 Sep & $90 \mathrm{AA}$ & 2.14 & 0.92 & 1.65 & 0.48 & 1.30 & 0.45 & 1.57 & 0.45 & 3.95 & 0.47 \\
\hline 7-13 Oct & $90 \mathrm{AA}$ & 1.82 & 0.91 & 1.57 & 0.20 & 1.29 & 0.20 & 1.31 & 0.17 & 2.63 & 0.42 \\
\hline 6-12 Nov & $90 \mathrm{AA}$ & 1.97 & 0.71 & 2.20 & 0.70 & 1.72 & 0.63 & 1.35 & 0.44 & 3.24 & 0.33 \\
\hline 6-12 Dec & $90 \mathrm{AA}$ & 1.94 & 0.72 & 1.90 & 0.36 & 1.51 & 0.35 & 1.55 & 0.35 & 2.80 & 0.37 \\
\hline Time & & \multicolumn{2}{|c|}{$\approx 0.2 \mathrm{~h}$} & \multicolumn{2}{|c|}{$\approx 0.4 \mathrm{~h}$} & \multicolumn{2}{|c|}{$\approx 0.4 \mathrm{~h}$} & \multicolumn{2}{|c|}{$\approx 1.3 \mathrm{~h}$} & \multicolumn{2}{|c|}{$\approx 1.2 \mathrm{~h}$} \\
\hline
\end{tabular}

The RMSE values reported in the tables indicate that, even for JAK, there is no significant difference in the performance of IW SLC and IW GRDH products. In the first case, the best fit with reference data was obtained using a window size of 64 pixels in azimuth and 128 pixels in range. In the second case, the best performance against the literature was given by an asymmetric window of 128 pixels in azimuth and 64 pixels in range. 
As for EW GRDH and EW GRDM products, the estimated flow velocities were significantly affected by the image lower resolution. Detailed results are not shown for brevity. Aggregated results will be provided at the end of this section.

\subsubsection{Thwaites Glacier}

The last analyzed glacier was the THW. The RMSE for the estimated flow velocities calculated against the reference literature for the 12 processed pairs is shown in Tables 10 and 11 for IW SLC and IW GRDH experiments. As for the other glaciers, the results are quite similar. Some pairs exhibited serious decorrelation issues, especially in the SLC case, where data on the pairs acquired in February, March and August were not retrievable. These couples (in addition to that acquired in November) were affected by the same problems using GRDH images but, in this case, the increase of the CC window had positive influence on the correlation, thus allowing for a reliable retrieval of the velocity field. The lack of any clear link to seasonal effects, such as ice melting during the Antarctic summer, suggests that correlation patterns can be significantly modified by varying the product type and that the pre-processing applied to data (standard TOPSAR, eventually followed by detection and resampling in the case of GRD images) can play a significant role in the calculation of the velocity field.

Table 10. THW, IW SLC product class experiments, RMSE (expressed in $\mathrm{m} /$ day) with respect to available literature data measured along selected along/across flow transects.

\begin{tabular}{|c|c|c|c|c|c|c|c|c|c|}
\hline \multicolumn{10}{|c|}{ Thwaites-IW SLC } \\
\hline \multirow{2}{*}{ Observation } & \multirow{2}{*}{ Track } & \multicolumn{2}{|c|}{$w=64, f=16 / 4$} & \multicolumn{2}{|c|}{$w=64 / 128, f=16 / 4$} & \multicolumn{2}{|c|}{$w=128, f=8 / 4$} & \multicolumn{2}{|c|}{$w=128 / 256, f=8 / 4$} \\
\hline & & Along & Across & Along & Across & Along & Across & Along & Across \\
\hline 9-15 Jan & 65 AA & 0.62 & 0.62 & 0.67 & 0.70 & 0.73 & 0.74 & 0.71 & 0.73 \\
\hline 20-26 Feb & $65 \mathrm{AA}$ & na & na & na & na & na & na & na & na \\
\hline 10-16 Mar & 65 AA & na & na & na & na & na & na & na & na \\
\hline 2-8 Jun & 65 AA & 1.17 & 1.28 & 1.13 & 1.37 & 1.11 & 1.34 & 1.08 & 1.35 \\
\hline 2-8 Jul & $65 \mathrm{DD}$ & 1.10 & 1.15 & 0.98 & 1.09 & 0.89 & 1.05 & 0.89 & 1.05 \\
\hline 1-7 Aug & 65 DD & na & $\mathrm{Na}$ & na & na & na & na & na & na \\
\hline 6-12 Sep & $65 \mathrm{DD}$ & 1.64 & 1.10 & 1.75 & 1.27 & 1.77 & 1.25 & 1.65 & 1.09 \\
\hline $6-12$ Oct & $65 \mathrm{DD}$ & 0.71 & 0.59 & 0.61 & 0.53 & 0.66 & 0.56 & 0.66 & 0.55 \\
\hline
\end{tabular}

Table 11. THW, IW GRDH product class experiments, RMSE (expressed in m/day) with respect to available literature data measured along selected along/across flow transects.

\begin{tabular}{|c|c|c|c|c|c|c|c|}
\hline \multicolumn{8}{|c|}{ Thwaites-IW GRDH } \\
\hline \multirow{2}{*}{ Observation } & \multirow{2}{*}{ Track } & \multicolumn{2}{|c|}{$w=64, f=8$} & \multicolumn{2}{|c|}{$w=128, f=8$} & \multicolumn{2}{|c|}{$w=256, f=4$} \\
\hline & & Along & Across & Along & Across & Along & Across \\
\hline 9-15 Jan & 65 AA & 0.95 & 0.90 & 0.84 & 0.87 & 1.07 & 1.00 \\
\hline 20-26 Feb & 65 AA & na & na & 1.64 & 1.51 & 1.71 & 1.51 \\
\hline 10-16 Mar & $65 \mathrm{AA}$ & na & na & na & na & 1.29 & 1.27 \\
\hline 9-15 Apr & $65 \mathrm{AA}$ & 1.55 & 1.20 & 1.41 & 1.21 & 1.47 & 1.26 \\
\hline 15-21 May & 65 AA & 1.55 & 1.28 & 1.70 & 1.45 & 1.49 & 1.30 \\
\hline 2-8 Jun & $65 \mathrm{AA}$ & 1.52 & 1.51 & 1.55 & 1.47 & 1.45 & 1.39 \\
\hline 2-8 Jul & $65 \mathrm{DD}$ & 1.33 & 0.99 & 1.43 & 1.31 & 0.84 & 0.73 \\
\hline 1-7 Aug & $65 \mathrm{DD}$ & na & na & na & na & 1.38 & 1.26 \\
\hline 6-12 Sep & 65 DD & 1.97 & 1.70 & 2.01 & 1.67 & 2.12 & 1.72 \\
\hline 6-12 Oct & $65 \mathrm{DD}$ & 1.28 & 1.28 & 1.20 & 1.20 & 1.26 & 1.23 \\
\hline 5-11 Nov & $65 \mathrm{DD}$ & na & na & 1.16 & 1.36 & 1.42 & 1.49 \\
\hline 5-11 Dec & 65 DD & 1.49 & 1.43 & 1.57 & 1.56 & 1.73 & 1.36 \\
\hline Time & & \multicolumn{2}{|c|}{$\approx 0.5 \mathrm{~h}$} & \multicolumn{2}{|c|}{$\approx 2.5 \mathrm{~h}$} & \multicolumn{2}{|c|}{$\approx 3.5 \mathrm{~h}$} \\
\hline
\end{tabular}




\subsubsection{Aggregated Results}

Aggregated results for all of the performed experiments and test sites are provided in Table 12 and in the four successive pictures. Data reported in the table represent the annual RMSE of the estimated velocities against reference data calculated as described in Equation (2) using now the annual average of the estimated and reference flow speeds. The average annual flow speed along the considered transects for all the products involved in the comparison is depicted in Figures 6-9 for PG, NI, JAK and THW, respectively.

Table 12. RMSE (expressed in $\mathrm{m} /$ day) against reference literature for the selected along/across flow transects for the four analyzed glaciers and product classes calculated by averaging one year of observations.

\begin{tabular}{ccccccccc}
\hline Glacier & \multicolumn{2}{c}{ IW SLC } & \multicolumn{2}{c}{ IW GRDH } & \multicolumn{2}{c}{ EW GRDH } & \multicolumn{2}{c}{ EW GRDM } \\
\hline & Along & Across & Along & Across & Along & Across & Along & Across \\
\hline Petermann & 0.10 & 0.20 & 0.17 & 0.24 & 0.32 & 0.50 & 0.53 & 0.66 \\
Nioghalvifierdsfjorden & 0.17 & 0.20 & 0.14 & 0.20 & na & na & 0.57 & 0.91 \\
Jackobshavn & 1.69 & 0.17 & 1.55 & 0.22 & 7.37 & 1.24 & 8.39 & 1.37 \\
Thwaites & 1.10 & 0.81 & 1.41 & 1.17 & na & na & 1.63 & 1.01 \\
\hline
\end{tabular}

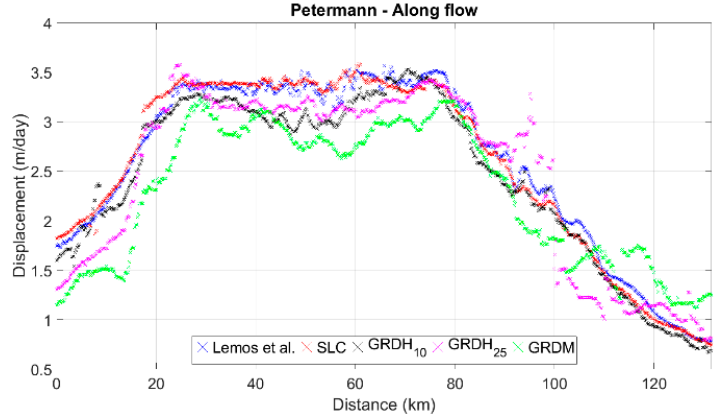

(a)

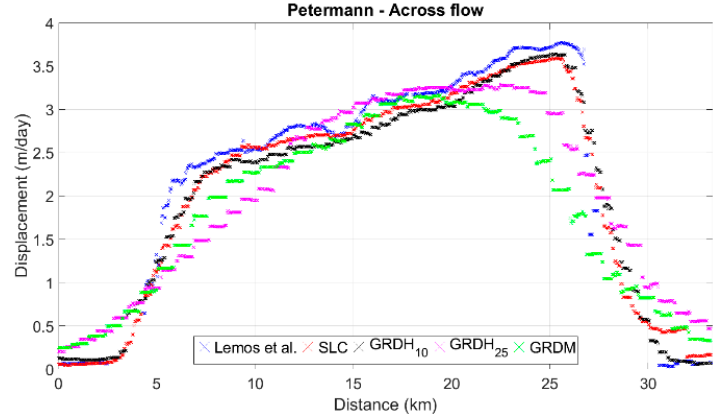

(b)

Figure 6. PG, average annual flow speed for reference data (blue curve) and all the analyzed products (IW SLC red curve, IW GRDH black curve, EW GRDH magenta curve, EW GRDM green curve). (a) Along flow speed. (b) Across flow speed.

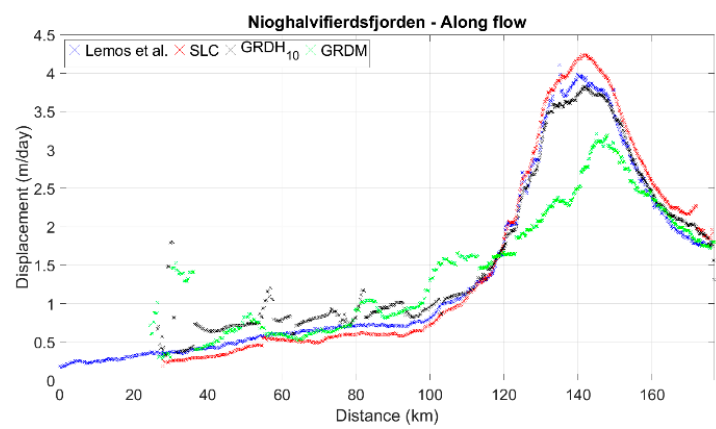

(a)

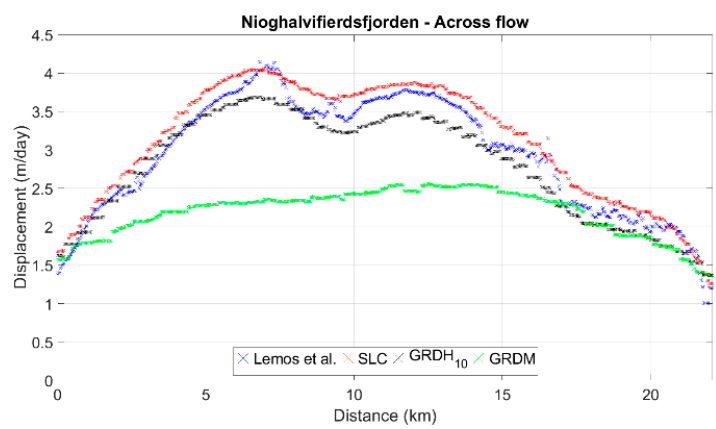

(b)

Figure 7. NI, average annual flow speed for reference data (blue curve) and all the analyzed products (IW SLC red curve, IW GRDH black curve, EW GRDM green curve). (a) Along flow speed. (b) Across flow speed. 


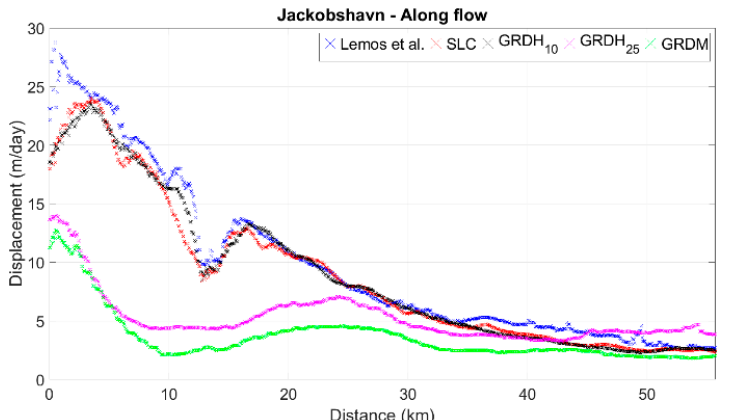

(a)

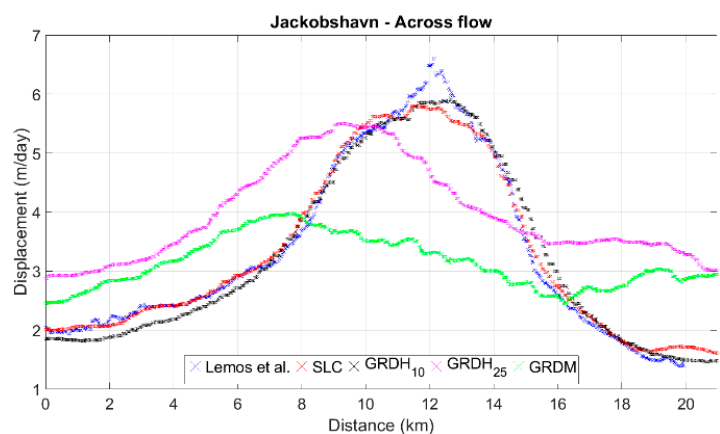

(b)

Figure 8. JAK, average annual flow speed for reference data (blue curve) and all the analyzed products (IW SLC red curve, IW GRDH black curve, EW GRDH magenta curve, EW GRDM green curve). (a) Along flow speed. (b) Across flow speed.

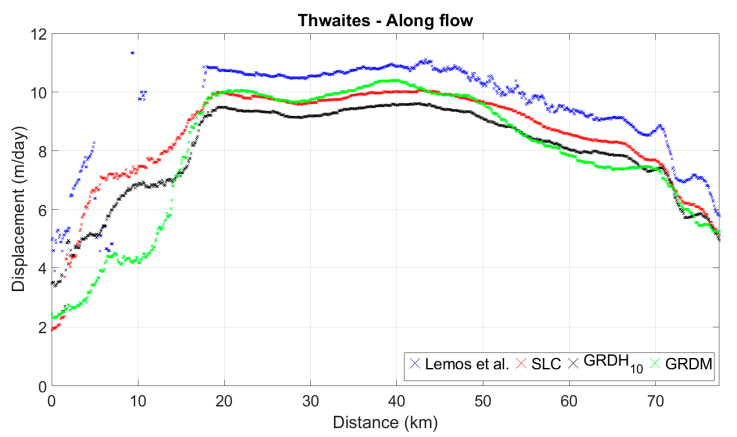

(a)

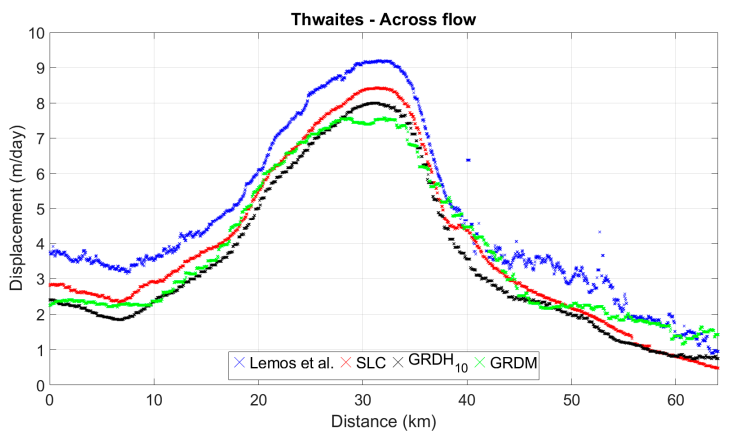

(b)

Figure 9. THW, average annual flow speed for reference data (blue curve) and all the analyzed products (IW SLC red curve, IW GRDH black curve, EW GRDM green curve). (a) Along flow speed. (b) Across flow speed.

From Table 12, it arises that for PG the performance of IW SLC and IW GRDH is fully comparable with respect to reference data, with registered RMSE of few tens of centimeters per day on the annual average in both along and across flow directions. The performance of EW products is still acceptable, although the retrieved velocity field is noisier at the edge of the glacier (see Figure $6 a, b$ ). Overall, a slight underestimation of the displacement velocity is registered whatever the product class is used if compared with reference data.

As for NI, the displacement velocity estimated using EW GRDH products is not fitting the reference distribution, as shown in Figure 7a,b. This is also confirmed by the RMSE values reported in Table 12, which are higher with respect to those calculated for IW SLC and IW GRDH images. As a general comment, the reference curves for the flow velocity for the along and across flow transects are almost in the middle of those retrieved using these products, with those relevant to IW SLC images placed slightly upper.

In the case of JAK, the differences between reference data and the results obtained by processing IW SLC and IW GRDH images are concentrated in the along flow direction, with particular reference to the first kilometers of the considered transect (see Figure 8a). Concerning the across flow direction, the velocity field here estimated does almost perfectly match the values provided by the reference literature (Figure $8 \mathrm{~b}$ ) as shown by the average RMSE in that direction, which is for both products of few centimeters per day.

As for EW products, both the GRDH and GRDM product class failed in the reconstruction of the velocity field of the JAK. As witnessed by the RMSE values reported in Table 12 and by the 
displacement velocity distributions depicted in Figure $8 \mathrm{a}, \mathrm{b}$, these product classes are not suitable for the monitoring of this glacier.

In the case of THW, the behavior of the analyzed product classes is quite consistent. For all of them, the trend is an underestimation of the displacement velocity with respect to reference data, with the underestimation increasing as the product resolution decreases. As reported in Table 12, the best registered performance against reference data is that of IW SLC products. Differences with respect to the results obtained using IW GRDH images arise especially in the along flow direction (see Figure 9a). In the across flow direction, the curves depicting the displacement velocity along the transect almost overlap, especially where the glacier exhibits its peak velocity (see Figure 9a).

The same considerations can be made for the EW GRDM product class. The discrepancy with respect to reference data is higher in the along flow direction, especially in the first and last kilometers of the transect. If the across flow direction is considered, the performance of this product class is in line with those of higher resolution data.

\subsection{Same Algorithm Comparison}

In the previous section, the velocity fields estimated by an in-house implemented OT algorithm were compared with the outputs from a commercial software to test the reliability of the solution. Here, the results are discussed fixing the algorithm and the parameter of the output flow velocity maps. In other words, the comparison will be implemented between algorithm runs leading to maps having comparable sensitivity and obtained with similar computational times.

In Table 13, data concerning PG (left panel) and NI (right panel) are reported. The reference velocity field is that obtained using IW SLC images as input for the in-house OT. In the case of PG, the reference experiments have been performed by setting the $C C$ window dimension to $64 \times 64$ square pixel and the oversampling factor to 16/4 in the azimuth/slant range directions, respectively. The same settings were applied to reference NI experiments.

Table 13. RMSE (expressed in $\mathrm{m} /$ day) for the displacement velocities calculated with the in-house OT algorithm with respect to reference IW SLC results for the PG (left panel) and NI (right panel).

\begin{tabular}{cccccccc}
\hline & \multicolumn{2}{c}{ Petermann } & \multicolumn{3}{c}{ Nioghalvifierdsfjorden } \\
\cline { 3 - 4 } Observation & \multirow{2}{*}{ Track } & \multicolumn{2}{c}{ IW GRDH } & Observation & Track & \multicolumn{2}{c}{ IW GRDH } \\
\cline { 3 - 4 } & & Along & Across & & & Along & Across \\
\hline 6-12 Jan & 26 AA & 0.17 & 0.36 & 3-9 Jan & 74 AA & 0.47 & 0.39 \\
11-17 Feb & 26 DD & 0.26 & 0.20 & 2-8 Feb & 74 AA & 0.47 & 0.59 \\
1-7 Mar & 26 DD & 0.32 & 0.30 & 4-10 mar & 74 AA & 0.42 & 0.49 \\
6-12 Apr & 26 DD & 0.26 & 0.35 & 15-21 Apr & 74 AA & 0.30 & 0.54 \\
18-24 May & 26 DD & 0.36 & 0.30 & 3-9 May & 74 AA & 0.30 & 0.67 \\
11-17 Jun & 26 DD & 0.44 & 0.92 & 2-8 Jun & 74 AA & 0.46 & 0.66 \\
11-17 Jul & 26 DD & 0.35 & 0.73 & 2-8 Jul & 74 AA & 0.28 & 0.30 \\
10-16 Aug & 26 DD & 0.26 & 0.69 & 1-7 Aug & 74 AA & 0.54 & 0.30 \\
9-15 Sep & 26 DD & 0.20 & 0.20 & 6-12 Sep & 74 AA & 0.64 & 0.32 \\
9-15 Oct & 26 DD & 0.14 & 0.22 & 6-12 Oct & 74 AA & 0.17 & 0.24 \\
8-14 Nov & 26 DD & 0.22 & 0.14 & 5-11 Nov & 74 AA & 0.20 & 0.36 \\
8-14 Dec & 26 DD & 0.33 & 0.17 & 5-11 Dec & 74 AA & 0.26 & 0.20 \\
Mean & & 0.20 & 0.10 & Mean & & 0.24 & 0.33 \\
\hline
\end{tabular}

Comparison data are shown only for IW GRDH images for brevity, also because this product class, together with the IW SLC, is showing the best agreement with the reference literature data. For both the PG and the NI, the OT setting for these experiments was CC window of $64 \times 64$ pixels and oversampling factor of 8 in both azimuth and slant range directions.

The table confirms that, as previously discussed, there are no significant differences in the displacement velocities estimated for the two product classes. In particular, for the PG, a peak 
RMSE of $0.44 \mathrm{~m} /$ day was recorded in the along flow direction, while for the across flow the highest MSE was of $0.92 \mathrm{~m} /$ day. Average values for the along flow and across flow RMSE were of 0.20 and $0.10 \mathrm{~m} /$ day respectively.

Similarly, for the NI, the peak values for the RMSE were of 0.64 and $0.67 \mathrm{~m} /$ day for the along flow and across flow directions, respectively. On average, the registered RMSE was of 0.24 and $0.33 \mathrm{~m} / \mathrm{day}$ for the two reference directions.

Data concerning JAK and THW are reported in the left and right panel of Table 14, respectively. As for the previous glaciers, only the comparison between reference IW SLC results and IW GRDH outputs is considered for brevity.

Table 14. RMSE (expressed in $\mathrm{m} /$ day) for the displacement velocities calculated with the in-house OT algorithm with respect to reference IW SLC results for JAK (left panel) and THW (right panel).

\begin{tabular}{|c|c|c|c|c|c|c|c|}
\hline \multirow{3}{*}{ Observation } & \multicolumn{3}{|c|}{ Jackobshavn } & \multicolumn{4}{|c|}{ Thwaites } \\
\hline & \multirow{2}{*}{ Track } & \multicolumn{2}{|c|}{$\mathrm{GRDH}_{10}$} & \multirow{2}{*}{ Observation } & \multirow{2}{*}{ Track } & \multicolumn{2}{|c|}{$\mathrm{GRDH}_{10}$} \\
\hline & & Along & Across & & & Along & Across \\
\hline 4-10 Jan & $90 \mathrm{AA}$ & 1.36 & 0.75 & 9-15 Jan & $65 \mathrm{AA}$ & 0.62 & 0.33 \\
\hline 15-21 Feb & $90 \mathrm{AA}$ & 1.19 & 0.20 & 20-26 Feb & $65 \mathrm{AA}$ & na & na \\
\hline 5-11 Mar & $90 \mathrm{AA}$ & 1.23 & 0.32 & 10-16 Mar & $65 \mathrm{AA}$ & na & na \\
\hline 4-10 Apr & $90 \mathrm{AA}$ & 1.79 & 0.30 & 9-15 Apr & $65 \mathrm{AA}$ & 1.12 & 1.18 \\
\hline 4-10 May & $90 \mathrm{AA}$ & 0.95 & 0.42 & 15-21 May & $65 \mathrm{AA}$ & 0.62 & 0.30 \\
\hline 3-9 Jun & $90 \mathrm{AA}$ & 0.95 & 0.56 & 2-8 Jun & $65 \mathrm{AA}$ & 0.64 & 0.24 \\
\hline 27-2 Aug & $90 \mathrm{AA}$ & 1.34 & 0.40 & 2-8 Jul & $65 \mathrm{DD}$ & 0.79 & 0.47 \\
\hline 20-26 Aug & 90 AA & 2.36 & 0.42 & 1-7 Aug & $65 \mathrm{DD}$ & na & na \\
\hline 13-19 Sep & $90 \mathrm{AA}$ & 1.38 & 0.36 & 6-12 Sep & $65 \mathrm{DD}$ & 0.57 & 0.69 \\
\hline 7-13 Oct & $90 \mathrm{AA}$ & 1.24 & 0.35 & $6-12$ Oct & $65 \mathrm{DD}$ & 0.74 & 0.85 \\
\hline 6-12 Nov & $90 \mathrm{AA}$ & 1.18 & 0.73 & 5-11 Nov & $65 \mathrm{DD}$ & 0.92 & 1.04 \\
\hline 6-12 Dec & $90 \mathrm{AA}$ & 0.90 & 0.26 & 5-11 Dec & $65 \mathrm{DD}$ & 0.72 & 0.45 \\
\hline Mean & & 0.67 & 0.17 & Mean & & 0.75 & 0.45 \\
\hline
\end{tabular}

As for JAK, data relevant to IW SLC experiments have been collected by setting the CC window to $64 / 128$ pixels and the oversampling factor to $8 / 4$ in the azimuth/slant range directions, respectively. In the IW GRDH experiments, the CC window was 128/64 pixels in azimuth/slant range direction, respectively, and the oversampling factor of 8 in both directions.

The highest performance difference between the two product classes is in the long track direction, with a peak RMSE of $2.36 \mathrm{~m} /$ day for the observation period 20-26 August 2017. For almost all the other pairs, the discrepancies are minor, leading to an average RMSE for the entire year of $0.67 \mathrm{~m} / \mathrm{day}$. The agreement between the results obtained using the two different product types is better in the across track direction, where the RMSE peak and yearly average recorded are 0.75 and $0.17 \mathrm{~m} /$ day, respectively.

The results on the THW were obtained, in the case of IW SLC images by setting the CC window to $128 / 256$ pixels and the oversampling factor to $8 / 4$ in azimuth/slant range directions, respectively. As for IW GRDH products, the CC window was set to $256 \times 256$ pixels and the oversampling factor to 8 for both directions.

The RMSE values calculated for both the along track and the across track directions are within the expected values. In the first case, the highest registered RMSE is 1.12 m/day for the pair 9-15 April 2017. All the other values are much lower than one meter per day, leading to a yearly average of $0.75 \mathrm{~m} / \mathrm{day}$.

In the across track direction, the peak RMSE, in the order of $1.18 \mathrm{~m} /$ day was registered for the same pair. In this case, the yearly average was of $0.45 \mathrm{~m} /$ day.

\subsection{Storage and Computational Times}

As discussed in the previous Sections, the computational time necessary to produce displacement maps with a sensitivity in the order of one meter in both the azimuth and slant range directions is 
roughly the same whatever the product class considered. This is because it is possible to balance the higher resolution of the input image with a lower oversampling factor and, on the other side, the lower resolution, requiring higher oversampling, by processing tiny subsets of the whole scan.

As an example, in the case of the PG, displacement maps with theoretical sensitivity of $0.9 \mathrm{~m}$ in both azimuth and slant range directions have been produced using IW SLC products as input in $1.5 \mathrm{~h}$ running a serial code on an 8-cores machine with 128 GB of RAM memory. Using IW GRDH products, a slightly lower theoretical sensitivity, in the order of $1.2 \mathrm{~m}$ in the two directions, has been obtained in approximately one-hour processing time. Computational times of the same order have been registered when producing maps with sensitivity of 1.6 and $2.5 \mathrm{~m}$ in the two directions using EW GRDH and EW GRDM products, respectively. For these products, however, the increase of the CC window dimension from $64 \times 64$ to $128 \times 128$ pixels had a destructive impact on computational times. Similar considerations hold for the other glaciers analyzed.

The scenario changes if storage needs reported in Table 15 are considered. It arises that, to process the four time-series using IW SLC products, approximately slightly less than one terabyte of data was archived to output one image per month. This means that, the exploitation of the full temporal resolution of the Sentinel-1 constellation, delivering up to one image every six days, would imply to multiply by four the amount of data processed in this work, with the total reaching approximately 4 terabytes for the considered glaciers.

Table 15. Storage needs (in GB) per analyzed time-series, processing step, and product class.

\begin{tabular}{ccccccc}
\hline Glacier & Level-1 & Coregistration & Subset & OT & Map & Product \\
\hline \multirow{3}{*}{ PG } & 93.1 & 78.8 & 62.5 & 62.5 & 0.35 & IW SLC \\
& 20.2 & 37.8 & 22.0 & 22.0 & 0.24 & IW GRDH \\
& 15.2 & 18.2 & 5.66 & 5.66 & 0.77 & EW GRDH \\
& 5.74 & 8.92 & 1.95 & 1.95 & 0.67 & EW GRDM \\
\hline \multirow{2}{*}{ NI } & 106 & 81.6 & 39.4 & 39.4 & 0.20 & IW SLC \\
& 22.9 & 37.8 & 13.2 & 13.2 & 0.15 & IW GRDH \\
& 6.07 & 8.66 & 2.21 & 2.21 & 0.27 & EW GRDM \\
\hline \multirow{3}{*}{ JAK } & 80.5 & 80.2 & 17.7 & 17.7 & 0.07 & IW SLC \\
& 17.7 & 38.3 & 3.91 & 3.91 & 0.04 & IW GRDH \\
& 17.6 & 19.2 & 1.70 & 1.70 & 0.17 & EW GRDH \\
& 6.54 & 9.30 & 0.45 & 0.45 & 0.11 & EW GRDM \\
\hline \multirow{2}{*}{ THW } & 51.6 & 77.3 & 36.7 & 36.7 & 0.28 & IW SLC \\
& 12.0 & 37.9 & 11.3 & 11.3 & 0.12 & IW GRDH \\
& 6.40 & 9.28 & 1.28 & 1.28 & 0.20 & EW GRDM \\
\hline
\end{tabular}

Using IW GRDH images, the total amount of data to be archived is less than 300 GB, about one third less than that required for the full resolution complex product class. This value further decreases using EW images up to less $100 \mathrm{~GB}$ exploiting the lowest resolution GRDM product class. These values do not consider any data compression technique.

\section{Discussion}

The SAR literature is rich in works addressing glacier monitoring using OT techniques and, currently, it is benefiting from the open data policy of ESA regarding acquisitions made under the aegis of Copernicus Programme. The improved access to images is boosting the research in this field, with particular focus on continuous monitoring. However, works addressing the problem at product level, offering insights into the different product types performance, are still missing.

OT methods, using a pair of SAR images, can detect movements of several meters with a good degree of approximation [31]. The accuracy of the estimated displacements depends on many factors including the resolution of input images, the magnitude of real displacements, the acquisition geometry and the correlation coefficient between the considered image patches [58]. These parameters are 
interconnected. Higher resolution images tend to maximize correlation at finer scale and should be preferred when dealing, as an example, with landslides [30,56]. Spatial decorrelation can be also due to orbital issues, i.e., differences in the acquisition geometry and/or large spatial baseline that, changing speckle patterns or the response of rugged terrains [35], can affect the amplitude and the sharpness of the correlation peak [59].

The general trend in the literature is to feed OT algorithms with complex images [25]. However, as demonstrated in the previous Section, the use of pre-processed detected images presents advantages at storage and computational level. Moreover, their performance is fully comparable with that of complex products, in particular in the case of the PG and of the NI, which are characterized by the smallest movements among the analyzed glaciers. A significant error of more than $2 \mathrm{~m} /$ day against reference data was registered for the JAK case study of August 2017 using SLC images with correlation windows of $64 \times 64$ square pixel and of 64 pixels in azimuth and 128 pixels in range. This can be due to the combination of effects given by the small correlation window and the flow velocity, which reach its peak in that month (see Table 2). A similar situation is observed in the IW GRDH case.

In some cases, it was not possible to retrieve the velocity field due to decorrelation issues. This happened for the PG using interferometric extra-wide swath products and for the THW Glacier using interferometric wide swath images, both complex and detected. In the first case, the decorrelation was likely due to orbital issues, since footprints appear quite squinted. The same did not occur for the THW Glacier, for which the acquisition geometries seem to be consistent. Moreover, an improvement of correlation was registered with the increase of the calculation window using detected images, and this allowed for a reliable estimation of the velocity field. Conversely, this was not possible exploiting complex products. This suggests that correlation patterns can be significantly modified varying the product type, and that they do not necessarily benefit from the enhancement of the resolution of the input product. The investigation of the effects of pre-processing and/or image parameters on the cross-correlation and, as a consequence, on the estimated velocity field, is an open point to be addressed with further research.

Moving to aggregated results (see Section 3.1.5), the most remarkable differences with respect to reference data arose for the JAK in the along flow direction, with particular reference to the first kilometers of the considered transect (see Figure 8a). Due to the lack of any ground data and the limited visibility of the algorithm implemented in the GAMMA-SAR software suite, it is difficult to understand which result better represents the real movement of this part of the glacier. However, the assessment of the best performing method is not the purpose of this paper which has focused on the study of the performance of different classes of SAR products. In this perspective, it is possible to argue that the performance of IW SLC and IW GRDH product classes is mostly equivalent. This is confirmed by the values of the RMSE reported in Table 12.

\section{Conclusions}

Since 2014, the Sentinel-1 mission of the European Space Agency has been providing high-quality synthetic aperture radar data allowing for more effective monitoring of our rapidly changing planet. Data are delivered in different formats and at different stages of the SAR pre-processing chain. However, only a few studies in literature are concerned with the assessment of the best product for a specific application. In this work, we compared the performance of all the Sentinel-1 product classes (interferometric wide swath single look complex, interferometric wide swath high-resolution ground range detected, extra-wide swath high-resolution ground range detected, and extra-wide swath medium-resolution ground range detected) in a classic radar remote sensing application, i.e., glacier monitoring using offset tracking.

To this end, four different glaciers (namely the Petermann Glacier, the Nioghalvifierdsfjorden, the Jakobshavn Isbræ and the Thwaites glacier) have been investigated using a state-of-the-art algorithm applied to couple of images acquired with short temporal baseline (6 to 12 days) during the year 2017. The obtained flow velocities were compared initially with reference literature data obtained 
using an offset tracking tool implemented in the commercial software suite GAMMA-SAR to test the reliability of the implemented solution. Then, the comparison moved at product level (i.e., fixing the offset tracking algorithm) to better understand each performance.

The results showed that the flow velocities retrieved along selected along/across flow transects by using interferometric wide swath products (both complex and detected) were in good agreement with literature data, although the implemented solution tend to slightly underestimate the flow velocities. However, the lack of ground data as well as of information on the algorithm implemented in the aforementioned commercial software suite makes it difficult to understand which solution better depicts the real phenomenon. As a general comment, the flow velocities obtained using complex and detected images were fully comparable. The most remarkable difference was observed in the case of the Thwaites Glacier, in both along and across flow directions, where complex product performed slightly better.

The passage to extra-wide swath images, instead, was disadvantageous, with results tending to drift more from the reference as the resolution of the input product decreases. Another point against these product classes is that the time span between two successive acquisitions on the same area is of 12 days in most of the cases (while for interferometric wide swath images is 6 days). This has a negative impact on the correlation between the image pairs and, consequently, on the estimated displacements.

The product-level comparison aimed at the analysis of the velocity field output by the same algorithm once fixed the parameters of the output map, i.e., theoretical sensitivity and the resolution, and it mainly confirmed what arose from the comparison with the literature. The performance of interferometric wide swath high-resolution ground range detected images was fully comparable with that of complex ones, with yearly averages of the root mean square errors calculated along the transects ranging from few centimeters to few tens of centimeters per day.

The major differences between the two product classes concern the pre-processing, applied to prepare the images for the ingestion in the core information process, and storage needs. Ground range detected images are ready-to-use data, which do not need any pre-processing before being ingested in the offset tracking algorithm. On the contrary, complex images must be compensated for the TOPSAR acquisition mode before being exploited for information extraction.

Storage needs greatly vary depending on the product class. Each step forward in the resolution (from the extra wide swath medium resolution to the full resolution complex) roughly implied quadrupling the storage capacity.

Summarizing, this work demonstrated that the performance of Sentinel-1 interferometric wide swath images, both complex and detected, are fully comparable, making them a perfectly interchangeable input for offset tracking procedures. However, detected images could be advantageous, for example in case of studies requiring short revisit times, due to their faster processing (as no pre-processing is required) and the lower storage demand. As for extra-wide swath images, the estimated flow velocities are highly affected by the lower resolution of the input products. Therefore, these product classes are not recommended for this kind of applications.

Author Contributions: Conceptualization, D.A.; methodology, D.A.; software, D.A. and G.D.M.; validation, D.A and G.D.M.; investigation, D.A.; resources, A.I. and R.G.; writing-original draft preparation, D.A.; writing-review and editing, R.G., G.D.M. and A.I.; supervision, A.I. and R.G.; funding acquisition, R.G.

Funding: This research received no external funding.

Conflicts of Interest: The authors declare no conflict of interest.

\section{Abbreviations}

List of the acronyms (in order of appearance):

S1

ESA

SAR

IW
Sentinel-1

European Space Agency

Synthetic Aperture Radar

Interferometric Wide swath 


$\begin{array}{ll}\text { EW } & \text { Interferometric Extra Wide swath } \\ \text { TOPSAR } & \text { Terrain Observation with Progressive Scanning SAR } \\ \text { SDH } & \text { Sentinels Data Hub } \\ \text { SLC } & \text { Single Look Complex } \\ \text { GRD } & \text { Ground Range Detected } \\ \text { GRDF } & \text { Full resolution Ground Range Detected } \\ \text { GRDH } & \text { High-resolution Ground Range Detected } \\ \text { GRDM } & \text { Medium resolution Ground Range Detected } \\ \text { SM } & \text { Stripmap } \\ \text { OT } & \text { Offset Tracking } \\ \text { PG } & \text { Petermann Glacier } \\ \text { NI } & \text { Nioghalvfjerdsfjorden } \\ \text { JAK } & \text { Jackobshavn Isbræ } \\ \text { THW } & \text { Thwaites Glacier } \\ \text { DInSAR } & \text { Differential Synthetic Aperture Radar Interferometry } \\ \text { CC } & \text { Cross-correlation } \\ \text { RMSE } & \text { Root Mean Square Error }\end{array}$

\section{References}

1. European Commission. Copernicus User Uptake-Engaging with Public Authorities, the Private Sector and Civil Society; Publications Office of the European Union: Luxembourg, 2016.

2. de Zan, F.; Guarnieri, A.M. TOPSAR: Terrain Observation by Progressive Scans. IEEE Trans. Geosci. Remote Sens. 2006, 44, 2352-2360. [CrossRef]

3. European Space Agency. Sentinel-1: ESA's Radar Observatory Mission for GMES Operational Services; ESA Communications: Noordwijk, The Netherlands, 2012.

4. Franceschetti, G.; Lanari, R. Synthetic Aperture Radar Processing; CRC Press: Boca Raton, FL, USA, 1999.

5. European Space Agency. Sentinel-1 Product Definition. Available online: http://sentinel.esa.int/documents/ 247904/1877131/Sentinel-1-Product-Definition (accessed on 30 May 2019).

6. Amitrano, D.; di Martino, G.; Iodice, A.; Riccio, D.; Ruello, G. Unsupervised Rapid Flood Mapping Using Sentinel-1 GRD SAR Images. IEEE Trans. Geosci. Remote Sens. 2018, 56, 3290-3299. [CrossRef]

7. Schubert, D.; Small, N.; Miranda, D.G.; Meier, E. Sentinel-1A Product Geolocation Accuracy: Commissioning Phase Results. Remote Sens. 2015, 7, 9431-9449. [CrossRef]

8. Lüttig, C.; Neckel, N.; Humbert, A. A combined approach for filtering ice surface velocity fields derived from remote sensing methods. Remote Sens. 2017, 9, 1062. [CrossRef]

9. Strozzi, T.; Luckman, A.; Murray, T.; Wegmüller, U.; Werner, C.L. Glacier motion estimation using SAR offset-tracking procedures. IEEE Trans. Geosci. Remote Sens. 2002, 40, 2384-2391. [CrossRef]

10. Riveros, N.; Euillades, L.; Euillades, P.; Moreiras, S.; Balbarani, S. Offset tracking procedure applied to high resolution SAR data on Viedma Glacier, Patagonian Andes, Argentina. Adv. Geosci. 2013, 35, 7-13. [CrossRef]

11. Lucchitta, B.K.; Ferguson, H.M. Antarctica: Measuring Glacier Velocity from Satellite Images. Science 1986, 234, 1105-1108. [CrossRef]

12. Lindstrom, D.; Tyler, D. Preliminary results of Pine island and Thwaites glaciers study. Antarct. J. U. S. 1984, 19, 53-55.

13. Bindschadler, R.A.; Scambos, T.A. Satellite-image-derived velocity field of an Antarctic ice stream. Science 1991, 252, 242-246. [CrossRef]

14. Emery, W.J.; Fowler, C.W.; Hawkins, J.; Preller, R.H. Fram strait satellite image-derived ice motions. J. Geophys. Res. Ocean 1991, 96, 4751-4768. [CrossRef]

15. Scambos, T.A.; Dutkiewicz, M.J.; Wilson, J.C.; Bindschadler, R.A. Application of image cross-correlation to the measurement of glacier velocity using satellite image data. Remote Sen. Environ. 1992, 42, 177-186. [CrossRef]

16. Bindschadler, R.A.; Vornberger, P.; Blanskenship, D.; Scambos, T.A.; Jacobel, R. Surface velocity and mass balance of Ice Streams D and E, West Antarctica. J. Glaciol. 1996, 42, 461-475. [CrossRef]

17. Bindschadler, R.A.; Fahnestock, M.A.; Skvarca, P.; Scambos, T.A. Surface-velocity field of the northern Larsen ice shelf. Ann. Glaciol. 1994, 20, 319-326. [CrossRef] 
18. Fahnestock, M.; Scambos, T.; Moon, T.; Gardner, A.; Haran, T.; Klinger, M. Rapid large-area mapping of ice flow using Landsat 8. Remote Sens. Environ. 2016, 185, 84-94. [CrossRef]

19. Armstrong, W.H.; Anderson, R.S.; Fahnestock, M.A. Spatial Patterns of Summer Speedup on South Central Alaska Glaciers. Geophys. Res. Lett. 2017, 44, 9379-9388. [CrossRef]

20. Li, T.; Liu, Y.; Li, T.; Hui, F.; Chen, Z.; Cheng, X. Antarctic surface ice velocity retrieval from MODIS-based mosaic of Antarctica (MOA). Remote Sens. 2018, 10, 1045. [CrossRef]

21. Dehecq, A.; Gourmelen, N.; Trouve, E. Deriving large-scale glacier velocities from a complete satellite archive: Application to the Pamir-Karakoram-Himalaya. Remote Sen. Environ. 2015, 162, 55-66. [CrossRef]

22. Kääb, A.; Winsvold, S.H.; Altena, B.; Nuth, C.; Nagler, T.; Wuite, J. Glacier remote sensing using Sentinel-2. part I: Radiometric and geometric performance, and application to ice velocity. Remote Sens. 2016, 8, 598. [CrossRef]

23. Paul, F.; Winsvold, S.H.; Kääb, A.; Nagler, T.; Schwaizer, G. Glacier remote sensing using Sentinel-2. part II: Mapping glacier extents and surface facies, and comparison to Landsat 8. Remote Sens. 2016, 8, 575. [CrossRef]

24. Wylie, D.P.; Jackson, D.L.; Menzel, W.P.; Bates, J.J. Global cloud cover trends inferred from two decades of HIRS observations. J. Clim. 2005, 18, 3021-3031. [CrossRef]

25. Joughin, R.; Smith, B.E.; Abdalati, W. Glaciological advances made with interferometric synthetic aperture radar. J. Glaciol. 2010, 56, 1026-1042. [CrossRef]

26. Goldstein, R.M.; Engelhardt, H.; Kamb, B.; Frolich, R.M. Satellite Radar Interferometry for Monitoring Ice Sheet Motion: Application to an Antarctic Ice Stream. Science 1993, 262, 1525-1530. [CrossRef]

27. Joughin, R.; Kwok, R.; Fahnestock, M.A. Interferometric Estimation of the Three-Dimensional Ice-Flow Velocity Vector Using Ascending and Descending Passes. IEEE Trans. Geosci. Remote Sens. 1988, 36, 25-37. [CrossRef]

28. Mattar, E.; Vachon, P.W.; Geudtner, D.; Gray, A.L.; Gumming, L.G.; Brugman, M. Validation of alpine glacier velocity measurements using ERS tandem-mission SAR data. IEEE Trans. Geosci. Remote Sens. 1998, 36, 974-984. [CrossRef]

29. Singleton, A.; Li, Z.; Hoey, T.; Muller, J.P. Evaluating sub-pixel offset techniques as an alternative to D-InSAR for monitoring episodic landslide movements in vegetated terrain. Remote Sens. Environ. 2014, 147, $133-144$. [CrossRef]

30. Amitrano, D.; Guida, R.; Dell'Aglio, D.; di Martino, G.; di Martire, D.; Iodice, A.; Costantini, M.; Malvarosa, F.; Minati, F. Long-Term Satellite Monitoring of the Slumgullion Landslide Using Space-Borne Synthetic Aperture Radar Sub-Pixel Offset Tracking. Remote Sens. 2019, 11, 369. [CrossRef]

31. Manconi, A.; Casu, F.; Ardizzone, F.; Bonano, M.; Cardinali, M.; de Luca, C.; Gueguen, E.; Marchesini, I.; Parise, M.; Vennari, C.; et al. Brief communication: Rapid mapping of landslide events: The 3 December 2013 Montescaglioso landslide, Italy. Nat. Hazards Earth Syst. Sci. 2014, 14, 1835-1841. [CrossRef]

32. Huang, J.; Deng, K.; Fan, H.; Yan, S. An improved pixel-tracking method for monitoring mining subsidence. Remote Sens. Lett. 2016, 7, 731-740. [CrossRef]

33. Fan, H.; Gao, X.; Yang, J.; Deng, K.; Yu, Y. Monitoring mining subsidence using a combination of phase-stacking and offset-tracking methods. Remote Sens. 2015, 7, 9166-9183. [CrossRef]

34. Joughin, I.; Smith, B.E.; Howat, I.M.; Scambos, T.; Moon, T. Greenland flow variability from ice-sheet wide velocity mapping. J. Glaciol. 2010, 56, 415-430. [CrossRef]

35. Yan, S.; Liu, G.; Wang, Y.; Ruan, Z. Accurate determination of glacier surface velocity fields with a DEM-assisted pixel-tracking technique from SAR imagery. Remote Sens. 2015, 7, 10898-10916. [CrossRef]

36. Sanchez-Gamez, P.; Navarro, F.J. Glacier Surface Velocity Retrieval Using D-InSAR and Offset Tracking Techniques Applied to Ascending and Descending Passes of Sentinel-1 Data for Southern Ellesmere Ice Caps, Canadian Arctic. Remote Sens. 2017, 9, 442. [CrossRef]

37. Wuite, J.; Rott, H.; Hetzenecker, M.; Floricioiu, D.; de Rydt, J.; Gudmundsson, G.H.; Nagler, T.; Kern, M. Evolution of surface velocities and ice discharge of Larsen B outlet glaciers from 1995 to 2013. Cryosphere 2015, 9, 957-969. [CrossRef]

38. Lanari, R.; Mora, O.; Manunta, M.; Mallorquí, J.J.; Berardino, P.; Sansosti, E. A small-baseline approach for investigating deformations on full-resolution differential SAR interferograms. IEEE Trans. Geosci. Remote Sens. 2004, 42, 1377-1386. [CrossRef] 
39. Bechor, N.B.D.; Zebker, H.A. Measuring two-dimensional movements using a single InSAR pair. Geophys. Res. Lett. 2006, 33, L16311. [CrossRef]

40. Sun, L.; Muller, J.P. Evaluation of the use of sub-pixel offset tracking techniques to monitor landslides in densely vegetated steeply sloped areas. Remote Sens. 2016, 8, 659. [CrossRef]

41. Peter, H.; Jäggi, A.; Fernández, J.; Escobar, D.; Ayuga, F.; Arnold, D.; Wermuth, M.; Hackel, S.; Otten, M.; Simons, W.; et al. Sentinel-1A-First precise orbit determination results. Adv. Space Res. 2017, 60, 879-892. [CrossRef]

42. Nick, F.M.; Luckman, A.; Vieli, A.; van der Veen, C.J.; van As, D.; van de Wal, R.S.W.; Pattyn, F.; Hubbard, A.L.; Floricioiu, D. The response of Petermann Glacier, Greenland, to large calving events, and its future stability in the context of atmospheric and oceanic warming. J. Glaciol. 2012, 58, 229-239. [CrossRef]

43. Rignot, E. Tidal motion, ice velocity and melt rate of Petermann Gletscher, Greenland, measured from radar interferometry. J. Glaciol. 1996, 42, 476-485. [CrossRef]

44. Rignot, E.; Steffen, K. Channelized bottom melting and stability of floating ice shelves. Geophys. Res. Lett. 2008, 35. [CrossRef]

45. Rignot, E.; Mouginot, J. Ice flow in Greenland for the International Polar Year 2008-2009. Geophys. Res. Lett. 2012, 39. [CrossRef]

46. Mayer, C.; Schaffer, J.; Hattermann, T.; Floricioiu, D.; Krieger, L.; Dodd, P.A.; Kanzow, T.; Licciulli, C.; Schannwell, C. Large ice loss variability at Nioghalvfjerdsfjorden Glacier, Northeast-Greenland. Nat. Commun. 2018, 9, 2768. [CrossRef] [PubMed]

47. Lemos, A.; Shepherd, A.; McMillan, M.; Hogg, A.E.; Hatton, E.; Joughin, I. Ice velocity of Jakobshavn Isbræ, Petermann Glacier, Nioghalvfjerdsfjorden, and Zachariæ Isstrøm, 2015-2017, from Sentinel 1-a/b SAR imagery. Cryosphere 2018, 12, 2087-2097. [CrossRef]

48. Enderlin, E.M.; Howat, I.M.; Jeong, S.; Noh, M.-J.; van Angelen, J.H.; van den Broeke, M.R. An improved mass budget for the Greenland ice sheet. Geophys. Res. Lett. 2014, 41, 866-872. [CrossRef]

49. Joughin, I.; Smith, B.E.; Shean, D.E.; Floricioiu, D. Brief Communication: Further summer speedup of Jakobshavn Isbræ. Cryosphere 2014, 8, 209-214. [CrossRef]

50. Holland, M.; Thomas, R.H.; de Young, B.; Ribergaard, M.H.; Lyberth, B. Acceleration of Jakobshavn Isbræ trig- gered by warm subsurface ocean waters. Nat. Geosci. 2008, 1, 659-664. [CrossRef]

51. Joughin, I.; Abdalati, W.; Fahnestock, M.A. Large fluctuations in speed on Greenland's Jakobshavn Isbræ glacier. Nature 2004, 432, 608-610. [CrossRef]

52. Scambos, T.A.; Bell, R.E.; Alley, R.B.; Anandakrishnan, S.; Bromwich, D.H.; Brunt, K.; Christianson, K.; Creyts, T.; Das, S.B.; DeConto, R.; et al. How much, how fast?: A science review and outlook for research on the instability of Antarctica's Thwaites Glacier in the 21st century. Glob. Planet. Chang. 2017, 153, 16-34. [CrossRef]

53. DeConto, R.M.; Pollard, D. Contribution of Antarctica to past and future sea-level rise. Nature 2016, 531, 591-597. [CrossRef]

54. Wegnüller, U.; Werner, C.; Strozzi, T.; Wiesmann, A.; Frey, O.; Santoro, M. Sentinel-1 Support in the GAMMA Software. Procedia Comput. Sci. 2016, 100, 1305-1312. [CrossRef]

55. Heo, Y.S.; Lee, K.M.; Lee, S.U. Robust Stereo matching using adaptive normalized cross-correlation. IEEE Trans. Pattern Anal. Mach. Intell. 2011, 33, 807-822. [PubMed]

56. Cai, J.; Wang, C.; Mao, X.; Wang, Q. An adaptive offset tracking method with SAR images for landslide displacement monitoring. Remote Sens. 2017, 9, 830. [CrossRef]

57. Kanade, T.; Okutomi, M. A stereo matching algorithm with an adaptive window: Theory and Experiment. IEEE Trans. Pattern Anal. Mach. Intell. 1994, 16, 920-932. [CrossRef]

58. Sun, L.; Muller, J.P.; Chen, J. Time series analysis of very slow landslides in the three Gorges region through small baseline SAR offset tracking. Remote Sens. 2017, 9, 1314. [CrossRef]

59. Yonezawa, C.; Takeuchi, S. Decorrelation of SAR data by urban damages caused by the 1995 Hyogoken-nanbu earthquake. Int. J. Remote Sens. 2010, 22, 37-41. [CrossRef]

(C) 2019 by the authors. Licensee MDPI, Basel, Switzerland. This article is an open access article distributed under the terms and conditions of the Creative Commons Attribution (CC BY) license (http://creativecommons.org/licenses/by/4.0/). 